\title{
Mass Transfer and Flow Characterization of Novel Algae Based Nutrient Removal System
}

\author{
Andreas Heyland ( $\nabla$ aheyland@uoguelph.ca ) \\ University of Guelph https://orcid.org/0000-0002-7592-4473 \\ Jeremy Chau \\ University of Guelph \\ Kevin Chai \\ University of Guelph \\ Andrew Eaton \\ University of Guelph \\ Kathleen Nolan \\ University of Guelph \\ Jordan Roszell \\ University of Guelph \\ Wael H. Ahmed \\ University of Guelph
}

Research

Keywords: Mass Transfer, Nutrient Removal System, Flow Characterization, Novel Algae, Recirculating aquaculture systems (RAS)

Posted Date: January 25th, 2021

DOl: https://doi.org/10.21203/rs.3.rs-151979/v1

License: (c) (1) This work is licensed under a Creative Commons Attribution 4.0 International License.

Read Full License

Version of Record: A version of this preprint was published at Biotechnology for Biofuels on April 26th, 2021. See the published version at https://doi.org/10.1186/s13068-021-01951-9. 


\title{
Mass Transfer and Flow Characterization of Novel Algae Based Nutrient Removal System
}

\author{
Andreas Heyland ${ }^{1}$, \\ University of Guelph \\ 50 Stone Rd E, \\ Guelph, Ontario, Canada \\ N1G 2W1 \\ aheyland@uoguelph.ca \\ Jeremy Chau, \\ University of Guelph \\ 50 Stone Rd E, \\ Guelph, Ontario, Canada \\ N1G 2W1 \\ Kevin Chai, \\ University of Guelph \\ 50 Stone Rd E, \\ Guelph, Ontario, Canada \\ N1G 2W1 \\ Andrew Eaton \\ University of Guelph \\ 50 Stone Rd E, \\ Guelph, Ontario, Canada \\ N1G 2W1 \\ eatona@uoguelph.ca

\section{Kathleen Nolan} \\ University of Guelph \\ 50 Stone Rd E, \\ Guelph, Ontario, Canada \\ N1G 2W1 \\ knolan@uoguelph.ca
}




\section{Jordan Roszell}

50 Stone Rd E,

Guelph, Ontario, Canada

N1G 2W1

jordan.roszell@gmail.com

Wael H. Ahmed ${ }^{1}$,

University of Guelph

50 Stone Rd E,

Guelph, Ontario, Canada

N1G 2W1

ahmedw@uoguelph.ca

1. Corresponding Authors 
ABSTRACT

Background: Recirculating aquaculture systems (RAS) are an essential component of sustainable inland seafood production. Still, nutrient removal from these systems can result in substantial environmental problems, or present a major cost factor with few added value options. In this study, an innovative and energy-efficient algae based nutrient removal system (NRS) was developed that has the potential to generate revenue through algal commercialization. We optimized mass transfer in our NRS design using novel aeration and mixing technology, using air lift pumps and developed an original membrane cartridge for the continuous operation of nutrient removal and algae production. Specifically, we designed, manufactured and tested a 60-liter NRS prototype. Based on specific airlift mixing conditions as well as concentration gradients, we assessed NRS nutrient removal capacity. We then examined the effects of different internal bioreactor geometries and radial orientations on the mixing efficiency.

Results: Using the start-up dynamic method, the overall mass transfer coefficient was found to be in the range of $0.00164-0.0074 \mathrm{~s}^{-1}$, depending on flow parameters and we confirmed a scaling relationship of mass transfer across concentration gradients. We found the optimal Reynolds number to be 500 for optimal mass transfer, as higher higher Reynolds numbers resulted in a relatively reduced increase of mass transfer. This relationship between mass transfer and Reynolds number is critical to assess scalability of our system. Our results demonstrate an even distribution of dissolved oxygen levels across the reactor core, demonstrating adequate mixing by the airlift pump, a critical consideration for optimal algal growth. Distribution of dissolved gases in the reactor was further assessed using flow visualization in order to relate the bubble distribution to the mass transfer capabilities of the reactor.

Conclusions: Manipulation of the concentration gradient across the membrane demonstrates a more prominent role of airlift mixing at higher concentration gradients. Specifically, the mass transfer rate increased 3-fold when the concentration gradient was increased 2.5-fold. Our findings provide support for scalibilty of the design and support the use of this novel NRS for nutrient removal in aquaculture and potentially other applications. 


\section{BACKGROUND}

With the growing demand for sustainable food production, land-based aquaculture is becoming an increasingly relevant alternative to existing approaches (Ahmed et al., 2019; Bjorndal and Tusvik, 2019). In recent years, inland aquaculture has grown rapidly as it presents a more environmentally sustainable way to produce seafood compared to aquaculture using natural water bodies (Costello et al., 2020). In situ pond and pen growth methods are known to experience frequent fluctuation in the surrounding water quality which can disturb the ecological balance required to maintain healthy growth conditions for aquatic livestock (Ariadi et al., 2019; Barbu et al., 2016). In comparison to these conventional aquaculture systems, inland recirculating growth systems can be operated under controlled conditions at high stock densities. Furthermore, inland aquaculture systems reduce area footprint as well as the overall water consumption of the aquaculture facility per unit lifestock or biomass produced (Timmons and Ebeling, 2010). Nevertheless, inland aquaculture requires high levels of maintenance and conventional methods for nutrient removal (nitrogenous waste - $\mathrm{NO} 2, \mathrm{NO} 3, \mathrm{NH} 4$, phosphate - $\mathrm{PO} 4$ and $\mathrm{CO}_{2}$ ) add to the production costs without adding revenue. Nutrient accumulation in RAS is attributed to decomposition of excess feed supplied to the system and also from the excretory and digestive byproducts released by the aquatic livestock into the system. Removal of these compounds is crucial, as high concentrations of nitrogenous and phosphate compounds can impact the growth and health of the aquatic livestock being reared and $\mathrm{CO}_{2}$ increase in RAS can lead to acidification (Timmons and Ebeling, 2010).

There are several methods currently implemented in recirculating aquaculture systems to remove nutrients from the water. Typically, this includes the removal of ammonia and other waste products $\left(\mathrm{NO}_{2}, \mathrm{NO}_{3}, \mathrm{NH}_{3}\right.$ and $\left.\mathrm{PO}_{4}\right)$. In order to reduce water loss, the sludge is typically thickened during this process which limits its downstream applications. These systems are also operated with smaller treatment volumes when compared to outdoor recirculating aquaculture systems (van Rijn, 2013). For outdoor systems, high rate algal ponds and wetlands have been employed (van Rijn, 2013). With these systems, the production of seafood can be combined to grow valuable biomass. However, these approaches and designs are highly dependent on the surrounding climatic conditions and require large treatment areas (van Rijn, 2013).

Microalgae are highly effective at removing nutrients from water and present an important alternative to bacterial denitrification systems (Choi and Lee, 2012). As photosynthetically active 
organisms, they can not only remove nitrogenous and phosphorous products but also $\mathrm{CO}_{2}$, which in tuas it is required for photosynthetic activity. Moreover, microalgae grow and clonally replicate within short time periods and are an extremely diverse group of organisms that provide a broad selection of species that can be acclimated to almost any effluent (Chisti, 2007, 2008; MorenoGarcia et al., 2017). More importantly, microalgal biomass has potential commercial applications, such as their use in the cosmetics, pharmaceutical and agricultural industries (Guedes et al., 2011; Renuka et al., 2018; Sathasivam and Ki, 2018). For example, several species of microalgae have been implemented in a variety of cosmetic products, providing companies with a relatively cheap source of valuable molecules to be used in hair and skin care products (Sathasivam and Ki, 2018; Spolaore et al., 2006). Microalgae species are also utilized to produce nutrient supplements; Specifically, Spirulina, Chlorella, and Dunaliella, have been shown to contain relatively high concentrations of carotenoid and vitamin B compounds, which are important for the health and well-being of several animals (Guedes et al., 2011; Tang and Suter, 2011). Furthermore, much research has explored microalgae as a dietary supplement for humans. Spirulina, Chlorella, Dunaliella, Haematococcus, Schizochytrium, and Isochyris have been shown to be nutrient rich and can be used as microalgae-based supplements for human consumption (Chacon-Lee and Gonzalez-Marino, 2010).

Within the agricultural and environmental sector, species such as Chlorella vulgaris and Spirulina platensis have been used as bio-fertilizers (Chisti, 2007, 2008) and some species have proven useful for phycoremediation of heavy metals, such as zinc $\left(\mathrm{Zn}^{2+}\right)$ and copper $\left(\mathrm{Cu}^{2+}\right)$, in water and soil (El-Sheekh et al., 2016). Recent studies of Zhu (Zhu et al., 2013) and Lee (Lee et al., 2015) have shown promising results for utilizing microalgae to sequester $\mathrm{CO}_{2}$ into algal biomass, convert nitrogen and phosphate to biomass via cellular incorporation, and to enrich the amount of dissolved oxygen in the water via the metabolic conversion of NADP+ to NADPH (Brune et al., 2009). In aquacultural facilities, microalgae have been implemented as a nutritionally-complete food item for aquatic larva and livestock (de la Noue and de Pauw, 1988).

One challenge of using microalgae in nutrient removal is their effective separation from the water that is used to culture organisms. Therefore, we developed a microalgal photobioreactor prototype (Fig. 1) that uses dialysis membrane to separate the RAS water from the algal culturing system in order to remove excess $\mathrm{CO}_{2}$ and nutrients without algal permeation. We also tested the effectiveness of a new airlift technology for mixing and enhancing the reactor's capacity for 
nutrient removal. We analyzed these innovations rigorously using non-dimensional parameters to scale the prototype reactor to an industrial scale. 


\section{RESULTS}

\section{Aeration and Mixing}

Experiments 1 and 2 were conducted in order to test the mixing and aeration in the reactor chamber as well as oxygen mass transfer under different operating conditions. In Experiment 1, we created horizontal profiles at five time points and detected only minimal variation in DO levels across the diameter of the reactor chamber (Fig. 2A). The center had a slightly higher dissolved oxygen level because the spiral airlift pump is located in that position. Empirically measured $\mathrm{O} 2$ concentrations at equilibrium matched those calculated using Henry's law (Fig. 2A). When testing DO level profiles for different membrane cartridge configurations, we found comparable patterns between the configurations as well as to the empty chamber (Fig. 2B).

A)

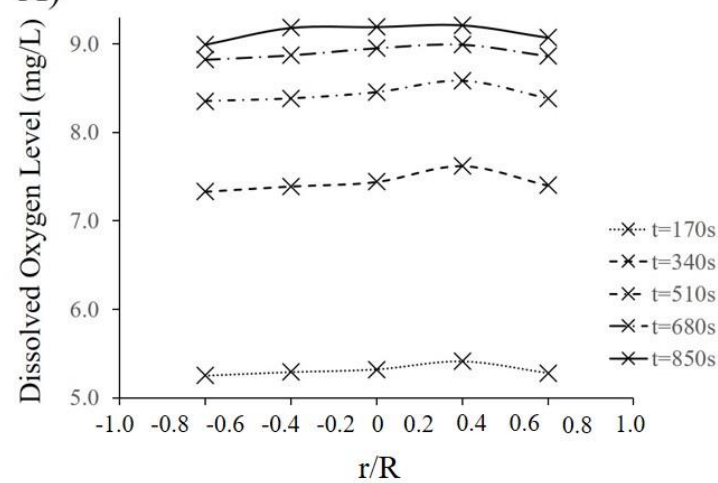

B)

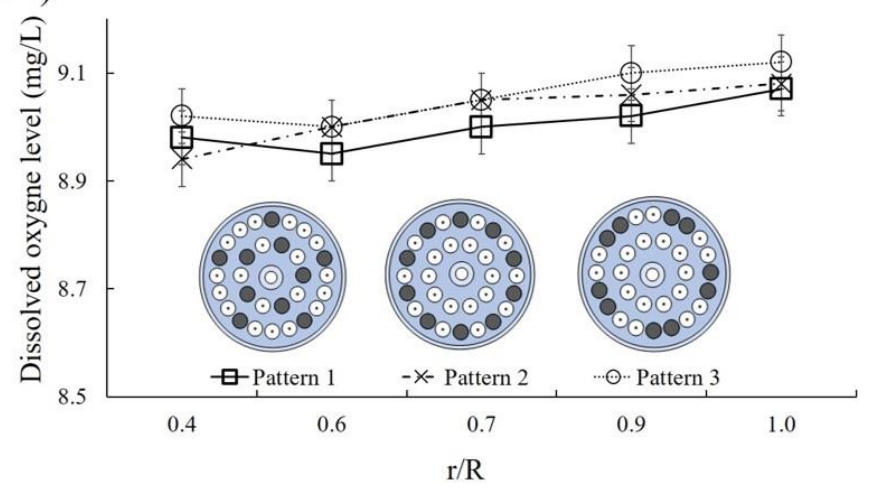

Figure 2: Radial profiles of dissoved oxygen levels within the reactor chamber. A) Radial profile across the full diameter of the reacor chamber without membrane cartridges measured at five time points from 170 s up to saturation at $850 \mathrm{~s}$. B) Radial profile across one half of the reactor chamber with three different membrane cartridge patterns present (used cartridges in dark blue).

In Experiment 2 we tested the consequences of different superficial gas flow rates ranging from $2.5 \mathrm{~L} / \mathrm{min}$ to $15 \mathrm{~L} / \mathrm{min}$ in the bioreactor in DO levels and oxygen mass transfer (Fig. 3). Overall, higher gas flow rate reach saturation faster (Fig. 3A-C). For instance, the dissolved oxygen level reached equilibrium at around 500 seconds ( 8.3 minutes) when the air flow rate was at $15 \mathrm{~L} / \mathrm{min}$, whereas it required around 957 seconds (15.9 minutes) to reach equilibrium when the air flow rate was at $7.5 \mathrm{~L} / \mathrm{min}$ (Fig. 3A). The gas flow rate has a strong influence on the mass transfer ability of an air-water system (Fig. 3D) and the overall mass transfer coefficient also has a positive linear correlation with an $\mathrm{R}^{2}$ value of 0.98 across the air flow rates tested. For example, 
when the air flow rate is at $2.5 \mathrm{~L} / \mathrm{min}$, the overall mass transfer is $0.001638 \mathrm{~s}^{-1}$, and as the air flow rate rises to $15 \mathrm{~L} / \mathrm{min}$, the overall mass transfer coefficient increases to $0.007413 \mathrm{~s}^{-1}$.

A)

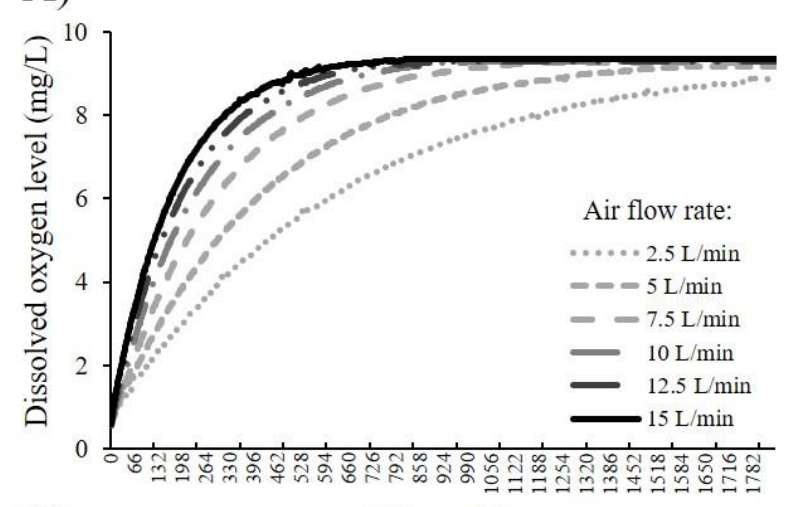

C)

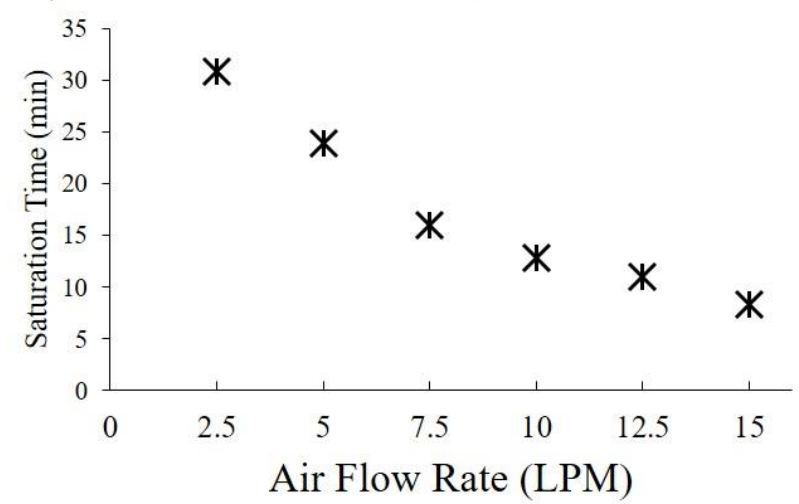

B)
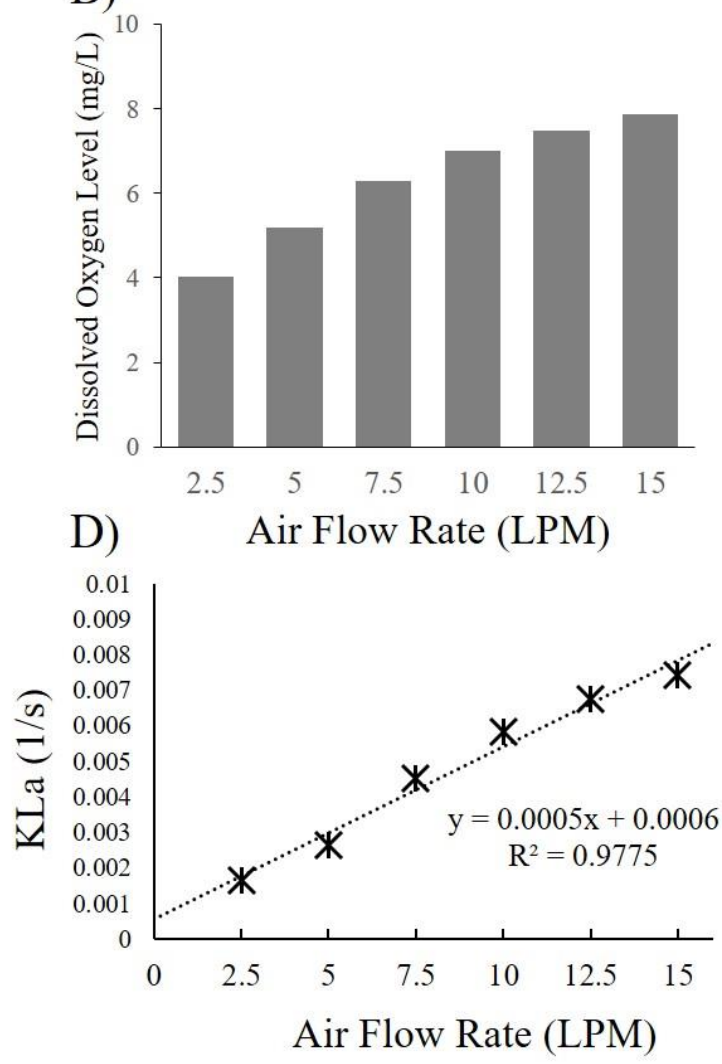

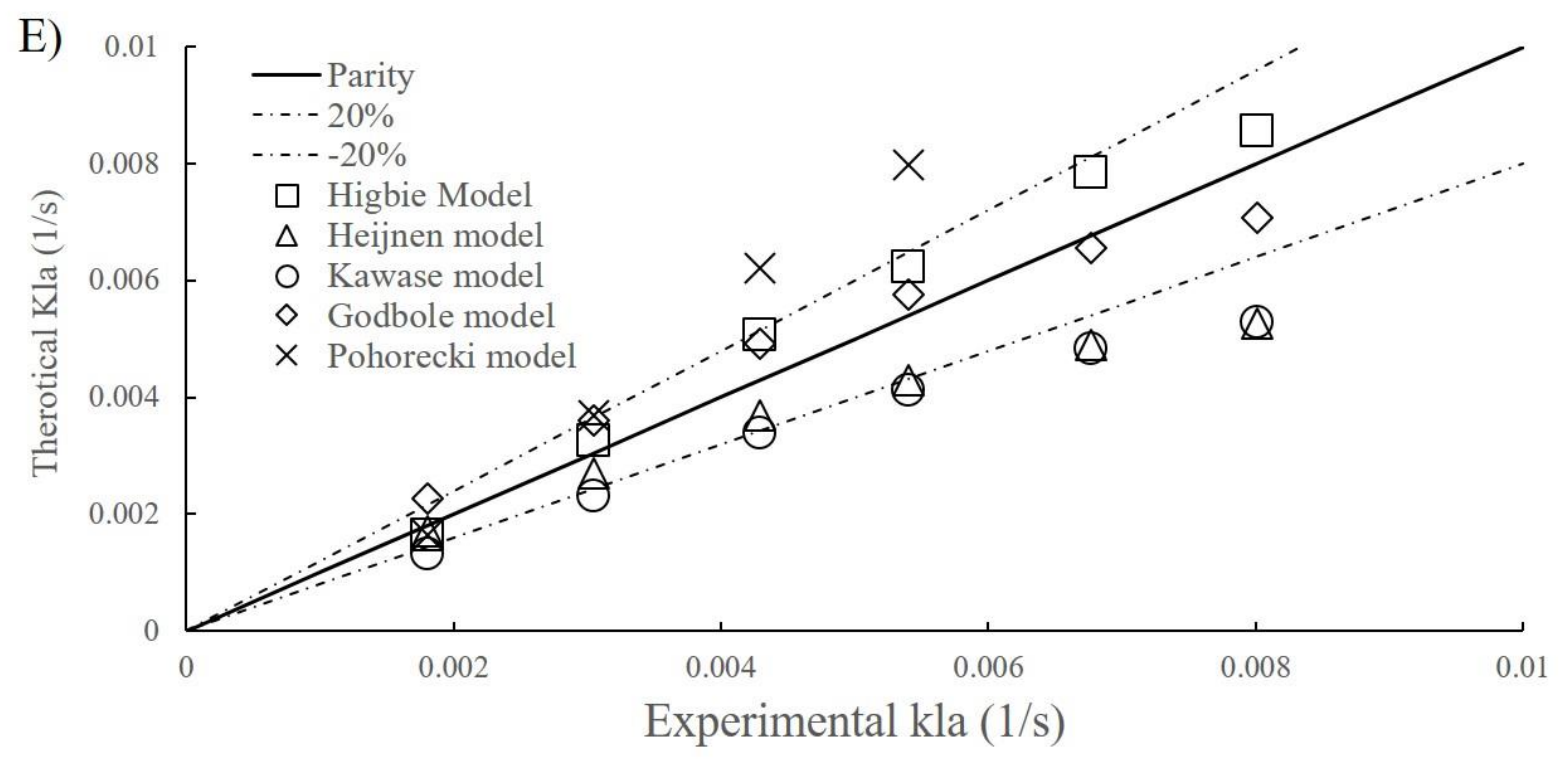


Figure 3: Dissolved oxygen (DO) level at various gas flow rates within the reactor chamber. A) DO as a function of time and six air flow rates. B) Average DO as a function of air flow rates. C) Saturation time ( $\mathrm{min}$ ) as a function of air flow rates. D) Calculated oxygen mass transfer rate as a function of air flow rate with linear regression model. E) Fitting of existing mass transfer models to the existing data.

We used the mass transfer coefficient data to compare our reactor column to several other mass transfer systems within bubble columns (Table 2). With all the mass transfer models tested, only the top five best fit correlations were selected for comparison and are shown in Figure 3E. All of these correlations are within the $40 \%$ error window and most of them lie within a $20 \%$ error range, with the exception of two datapoints for the Pohorecki model. To further study the models, we implemented the mean absolute percentage deviation (MAPD - equation 11) in order to assess the accuracy of the correlation between the model and our experimental results. Both the Higbie model and the Godbole model resulted in an MAPD value that is less than 15\%, which indicates that the model is a fairly good fit to the parameter of this project.

$$
M A P D=\frac{100 \%}{n} \sum_{t=1}^{n}\left|\frac{A_{t}-F_{t}}{A_{t}}\right|
$$

In Experiment 3 we characterized the bubble pattern and void fraction in response to the specified gas flow range. Figure 4 shows that the flow pattern within the reactor remained in bubbly flow and low gas flow. However, as the gas flow rate increased, the bubbles started to coalesce and form bigger bubbles that spread out further (Figure 4). Furthermore, the void fraction of gas in the reactor increases with increasing gas flow as expected, as there is a larger portion of gas in the system. At a gas flow rate of $2.5 \mathrm{~L} / \mathrm{min}$, the void fraction is around $12 \%$, and as the flow rate rises to $15 \mathrm{~L} / \mathrm{min}$, the void fraction reaches around $28 \%$. These results indicate that the relationship is not linear and that the saturation of the void fraction occurs at higher gas flow rates. 
A)

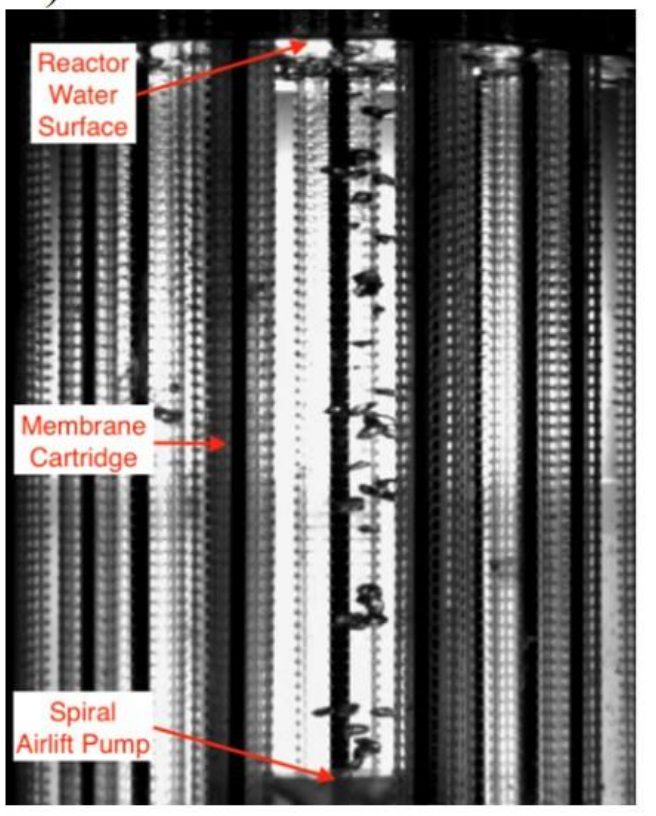

B)
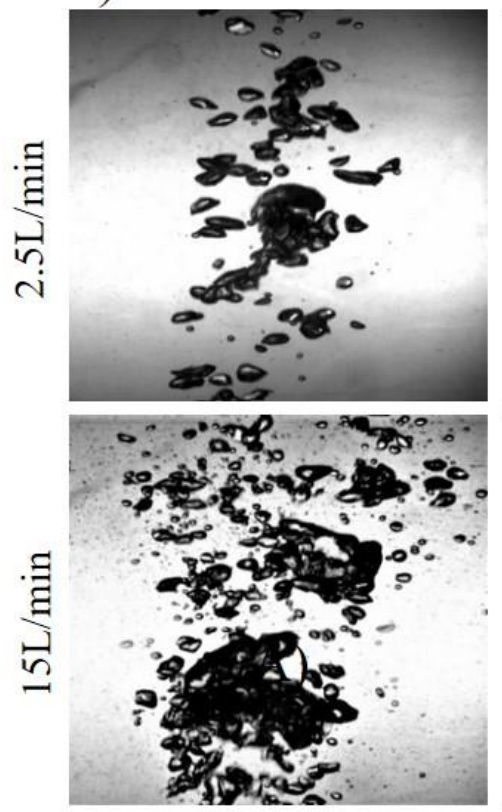

$\mathrm{P}$
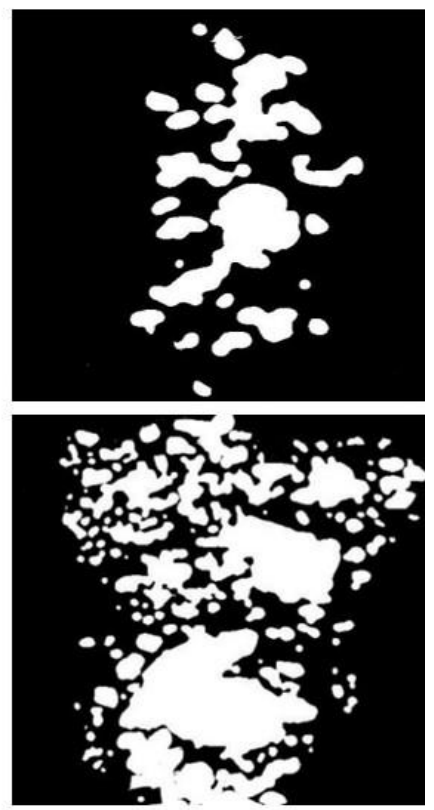

C)

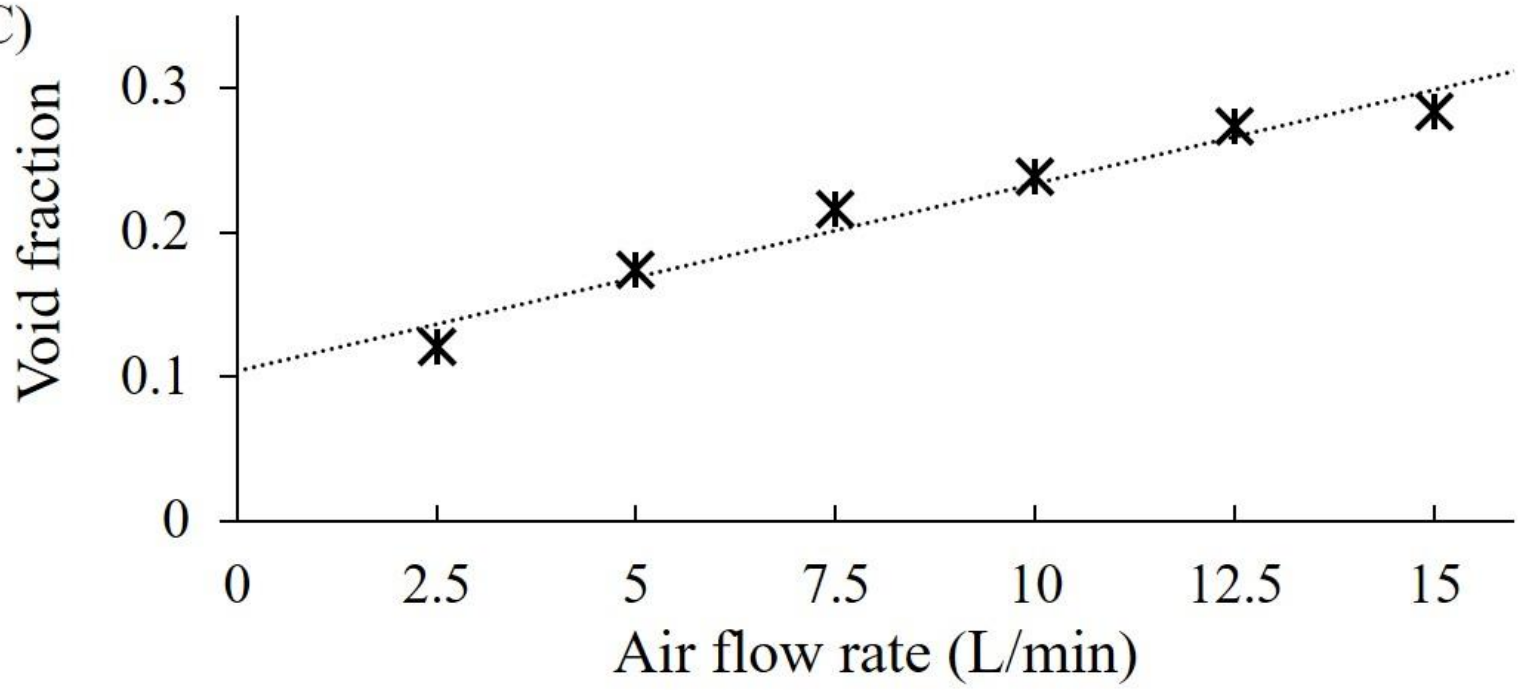

Figure 4: Multiphase flow visualization during reactor operation (A) and empirical assessment of air void fraction with the reactor chamber $(\mathrm{B}, \mathrm{C})$. A) image of reactor chamber using high speed camera setup. B) Representative high speed frames of lowest (2.5 L/min) and highest (15 $\mathrm{L} / \mathrm{min}$ ) air flow rates with processed images used for analysis. Complete set of representative images across the entire range can be found in Supplement 1. 
Membrane Cartridge Mass Transfer Characteristics

Comprehensive experiments were conducted to characterize the effects of various operational parameters on the mass transfer rates for the prototype algae bioreactor. Figure 5 (A-C, G) illustrates the increase of mass transfer as a function of the salt gradient. Quantitatively, the mass transfer scales directly with the concentration gradient. When decreasing the concentration gradient from 5 to $2 \mathrm{ppt}$ (reduction factor of 2.5) the average mass transfer rate reduces from 7.72 to $2.81 \mathrm{~g} / \mathrm{hr}$, corresponding to a reduction factor of 2.7 . Similarly, reducing the initial salt gradient from 2 to $1 \mathrm{ppt}$, the average mass transfer rate dropped to $1.26 \mathrm{~g} / \mathrm{hr}$, for a reduction factor of 2.21. In addition, these experiments show that both water flow rate through the membrane cartridge as well as air flow rate in the reactor column affect the mass transfer rate. However, the impact of air flow is minimal at low salinity gradients and becomes more substantial at higher gradients. Specifically, we did not measure any substantial effect of water and air flow on mass transfer rate when the salinity gradient was 1 ppt. At 2ppt, mass transfer rate increased slightly with both water and air flow. The strongest impact of water and air flow was observed at 5ppt with the highest mass transfer rates resulting from high water flow rate (15 LPM) and air flow rate (14 LPM). When we tested the impact of increased membrane surface area on mass transfer we identified a surfacearea to volume ratio of 0.18 to produce maximum mass transfer rates (Fig. $5 \mathrm{H}$ ).

When we transformed these mass transfer rates into dimensionless parameters (Sherwood number and Reynolds number - Figure 5D-F) we found that mass transfer rates scale proportionally across salinity gradients. Additionally, increasing the air flow rate at a given Reynolds number and concentration reduced the Sherwood number. However, the Sherwood number has a tendency to plateau at higher Reynolds numbers $(\sim \operatorname{Re}=500)$. 

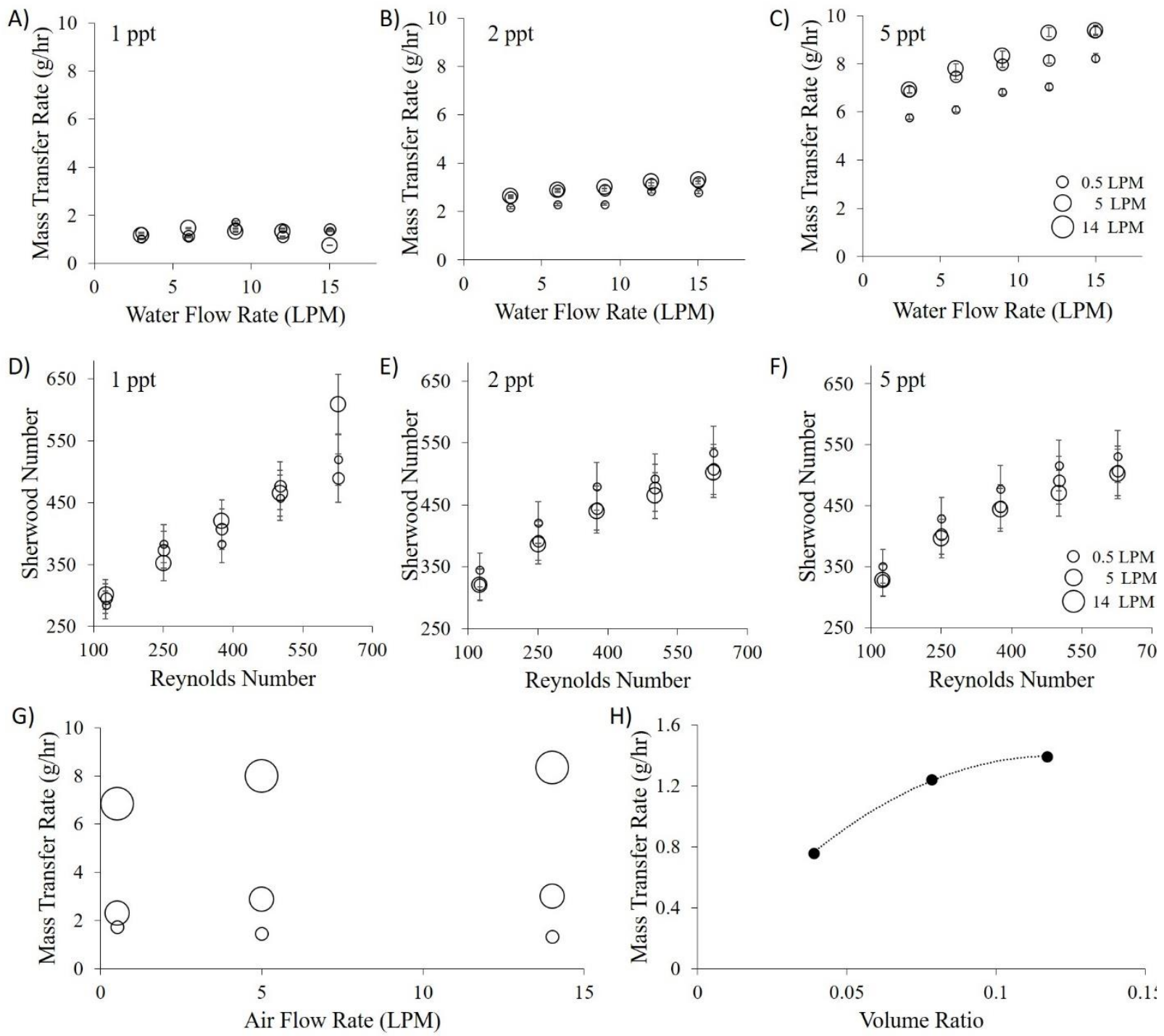

Figure 5: Salt mass transfer rates as a result of five water flow rates and three air flow rates across three salinity gradients (A-C). Calculated non-dimensional plots based on mass transfer values across three salinity gradients (D-F). G) Summary of mass transfer rates as a function of three air flow rates (0.5LPM, 5LPM and 14LPM) and three salinity gradients (1ppt, 2ppt and $5 p p t$ - represented by increasing sized circles) with membrane cartridges present. H) Mass transfer rate across membrane cartridges as a function of volume ratio of cartridges occupied. 


\section{DISCUSSION}

We conducted a series of experiments in order to assess basic mixing and aeration effects on mass transfer rates within a novel photobioreactor. We designed this photobioreactor for nutrient removal in recirculating aquaculture systems. For simplicity we conducted experiments using salt gradients as they can be measured accurately in real time. Still these measurements are comparable to actual nutrient transfer rates that will be assessed in future experiments.

The photobioreactor design we developed consists of three interconnected spaces with diffusion of ions and gases (Figure 1): 1) diffusion of ion and water across the membrane cartride, 2) diffusion of gases within the reactor chamber and 3) diffusion of gases from air bubbles created by the airlift pump into the reactor chamber. As the photobioreactor will be operated with algae in the reactor chamber and waste water flowing through the membrane cartridge, the relevant mass transfers are: 1) oxygen transfer from reactor chamber into waste water stream, 2) $\mathrm{CO}_{2}$ transfer from waste water stream into the reactor chamber, 3) $\mathrm{CO}_{2}$ transfer from bubble column into the reactor chamber, and 4) nutrient transfer from waste water stream into the reactor chamber. The measurements presented here provide critical insight into all of these potential mass transfer rates and therefore the efficient operation of this reactor design.

Mixing and mass transfer properties across reactor compartments

Proper mixing of water, algae and gases in the reactor chamber is critical to accomplish maximum growth rates (Ugwu et al., 2008). We were able to confirm a homogenous distribution of oxygen within the reactor under the operating conditions tested, including the addition of membrane cartridges that can potentially obstruct mixing. Furthermore, the oxygen saturation curves we generated across a range of air flow rates show that even under the lowest air flow rate we can reach saturation after 30 minutes. This is a sufficient time frame for operating this algal reactor.

With respect to the oxygen mass transfer models we tested, both the Higbie (1935) model and the Godbole (1984) model resulted in a fairly good fit. The Higbie (1935) model, also known as the penetration theory, has been widely used for finding the mass transfer in a bubble column. The Godbole (1984) model is an empirical equation that estimates the $k_{L} a$ value in the bubble column by establishing the relationship between the $k_{L} a$, the superficial gas velocity, and the fluid viscosity. The first part is the mass transfer coefficient $k_{L}$ which is related to the mass transfer 
rate in the diffusion process, and the second part is the effective interfacial area $a$ which is related to the area of the interface where the reaction takes place. The constant and the exponent can be changed according to the flow conditions and the fluid used in the system. This equation can also be used if a non-Newtonian fluid is used. When increasing the volume of the growth chamber of the reactor prototype, this model can also be used to predict the required air flow rate to accomplish appropriate mixing.

Characterizing the multiphase flow mixture inside the bioreactor body with the membranes installed is an important element to the design of the overall system. Key properties that are needed to characterize the mixing include bubble shape and size, rising velocity, turbulence and induced secondary flows (Cui et al., 2003). A flow visualization was used to relate the bubble distribution and the void fraction in the bioreactor system. As the air flow rate increases, the size of the bubbles and the amount of bubbles also increase. Therefore, the void fractions are strongly correlated with bubble size and the flow pattern in the reactor. We observed coalescence of bubbles at higher air flow rates, explaining the slight saturation of the void fraction. Typically, perforated plates are used in photobioreactors to break up coalesced bubbles in taller reactors (Singh and Sharma, 2012). Still, in our experiments, these larger bubbles can also rise faster than smaller bubbles, contributing to higher turbulence and mixing within the chamber. We also observed that in general, the dissolved oxygen concentration across the bioreactor diameter was evenly distributed. For each time interval, the differences in the dissolved oxygen concentration was within $0.2 \mathrm{mg} / \mathrm{L}$. This is mainly because the spiral airlift pump creates a vortex in the bioreactor, so the liquid inside the bioreactor is well mixed, and thus the dissolved oxygen level is evenly distributed. We also noticed a higher level of spiral mixing at these high flow rates which will be a critical component to consider when the reactor chamber is expanded in volume, while maintaining a similar diameter. In this case, larger bubbles and spiral injection will ensure proper mixing along the entire length of the reactor. This is a distinct advantage of our design over existing spargers, that typically have reduced back mixing at low gas flow rates (Janssen et al., 2003).

Our experiments were designed to assess the volumetric mass transfer behaviour of a bioreactor using a spiral airlift pump. Our multi-dimensional assessment of air/water flow rate and salinity gradient revealed an increase in mass transfer with increased flow rate inside the membrane tube. These results are consistent with theory in that the flow boundary layer inside the tube is reduced at higher velocities, leading to relatively higher salt ion concentrations in proximity of the 
membrane and therefore increasing the diffusion rate. These ions are then transported through the membrane via diffusion at low pressures $(<34.5 \mathrm{kPa})$ and a combination of diffusion and convection at higher pressures. This effect is enhanced by air injection, as it disrupts boundary layer effects on the reactor chamber side of the membrane. Still, operating the reactor at high (5LPM and more) air injection rates resulted in irregularities in mass transfer, suggesting that air flow rates should be kept minimal to optimize mass transfer at Reynolds numbers around 500 (the Re number we estimate to be optimal for operating our reactor). We hypothesize that turbulent flow at higher levels of air injection causes pressure fluctuations at the fresh water-membrane interface and disrupts the diffusion of salt ions through the membrane. It has also been shown in previous studies that turbulent flow can generally enhance growth rates of algae in photobioreactors (Bosca et al., 1991; Javanmardian and Palsson, 1991)

Reactor scaling and aquaculture implementation

In recirculating aquaculture operations, the daily nitrogen budget of a production system is typically known and allows to make specific predictions about nutrient removal requirements based on acceptable concentration of nitrate and other nutrients in the system (Martins et al., 2010; Schuster and Stelz, 1998). Our trials with salt water gradients revealedrevealed a predicted mass transfer rate from the membrane cartridge into the reactor chamber of $0.5 \mathrm{~kg} / 24 \mathrm{~h} /$ reactor, assuming optimal operating conditions as they were determined in this study. While this value is based on the small 60L prototype reactor and a 50\% membrane surface capacity, it allows to make certain predictions about the scalability and application of our new reactor technology. Specifically, the use of dimensionless parameters, Rn for fluid dynamics and Sherwood number for mass transfer, allows us to extrapolate the reactor properties beyond the dimensions of the current prototype. This is a crucial aspect of our study, as scalability can frequently be a difficult aspect of photobioreactor design (Ugwu et al., 2008).

Aeration of the reactor chamber is crucial for mixing; however, other parameters such as bubble size and velocity can impact the growth and health of algae in the reactor. For example, previous work has shown that lipid production by Chlorella sp. is negatively impacted by larger bubble sizes in the reactor, likely due to physical stress on the cells (Yang et al., 2018). Larger bubbles also result in poorer mass transfer of oxygen and $\mathrm{CO}_{2}$ in photobioreactors (Ugwu et al., 2008), a problem that can be addressed by breaking up larger bubbles within the reactor column 
using perforated plates (Singh and Sharma, 2012). While we did not test specific algal species in the current study, these parameters need to be considered when optimizing air and water flow rates. Moreover, the mixing also allows more efficient light usage inside the reactor chamber and therefore algal growth at higher concentrations (Ugwu et al., 2008). This is a critical consideration, as space can be limiting in algal production settings.

Vertical-column photobioreactor are generally considered easy to operate and can be used for large-scale culturing (Sánchez Mirón et al., 2002). With the addition of bubble column and airlift technology, as in our design, these reactors can achieve similar algae production rates as narrow tubular reactors by using less space and resulting in less clumping and settlement inside the tubes (Couvert et al., 2004). Additionally, our reactor design has the ability to transfer nutrients efficiently from a waste water stream into the algae compartment, without getting the algae directly into contact with the waste water. This latter design component is very suitable for inland aquaculture, as it significantly reduces the risk of cross contaminating production systems. 
CONCLUSION

In conclusion, we designed, built and tested a new NRS with state of the art bubble column and airlift technology for the continuous operation of nutrient removal and algae production. The NRS nutrient removal capacity was assessed based on radial conceneration gradients. Also, the concentration of dissolved gases in the reactor was assessed using flow visualization in order to relate the bubble distribution to the mass transfer capabilities of the reactor. The optimal Reynolds number was found to be 500 for optimal mass transfer, and this was found to be a critical parameter to assess scalability of our system. The results also demonstrate an even distribution of dissolved oxygen levels across the reactor core, demonstrating adequate mixing by the airlift pump, a critical consideration for optimal algal growth. Moreover, the experimental data for oxygen and salt mass transfer suggests that the present design is highly applicable to inland aquaculture settings, where excess nutrients need to be removed from the production system in order to ensure the healthy growth of animals. Specifically, the mass transfer rate increased 3-fold when the concentration gradient was increased 2.5-fold. Finally, the findings of the present work provide support for scalibilty of the design and support the use of this novel NRS for nutrient removal in aquaculture. 
MATERIALS AND METHODS

Experimental Setup

The photobioreactor is divided into three main subsystems that, when operating together, can remove molecules of small molecular size, including nutrients, from wastewater supply streams (Fig. 1A-B). These subsystems include: 1) the algae reactor body, 2) the wastewater recirculation loop (Fig. 1A), and 3) the membrane cartridge (Fig. 1B). The prototype algae column consists of a $60 \mathrm{~L}$ cylindrical acrylic tank with an inner diameter of $0.30 \mathrm{~m}$ and a height of $0.63 \mathrm{~m}$. The design of the membrane cartridge, shown in Figure 1B, allows nutrients to move to the algae chamber from an external wastewater supply. The membrane cartridge is designed to facilitate the transfer of these compounds and $\mathrm{CO}_{2}$ into the algae chamber via diffusion driven by concentration and pressure gradients. Additionally, as the algae metabolize $\mathrm{CO}_{2}$ and nutrients to produce $\mathrm{O}_{2}$ via photosynthesis, the dissolved oxygen content in the algae chamber will rise and will ultimately be transferred to the flow stream inside the membrane cartridge. Hence, the primary function of the algae reactor body is to provide a suitable environment for the algae to grow. As a substitute for traditional mixing methods, such as mechanical paddles and motors which can require maintenance due to algal caking, the prototype photo-bioreactor makes use of multiphase flow technology and we implemented a spiral injection airlift pump developed by FloNergia ${ }^{\mathrm{TM}}$ (Fig. 1). This system injects air into the algal chamber which creates a three-phase mixture of water, air, and algae. As the bubbles rise, they induce a circulation effect to enable effective mixing of algae. Additionally, the water chemistry can be controlled by changing the composition of the gas that is injected in order to optimize the algae growth rate. For example, the injection of $\mathrm{CO}_{2}$ may complement existing $\mathrm{pCO}_{2}$ which may be beneficial for some algae species (Mohsenpour and Willoughby, 2016). 

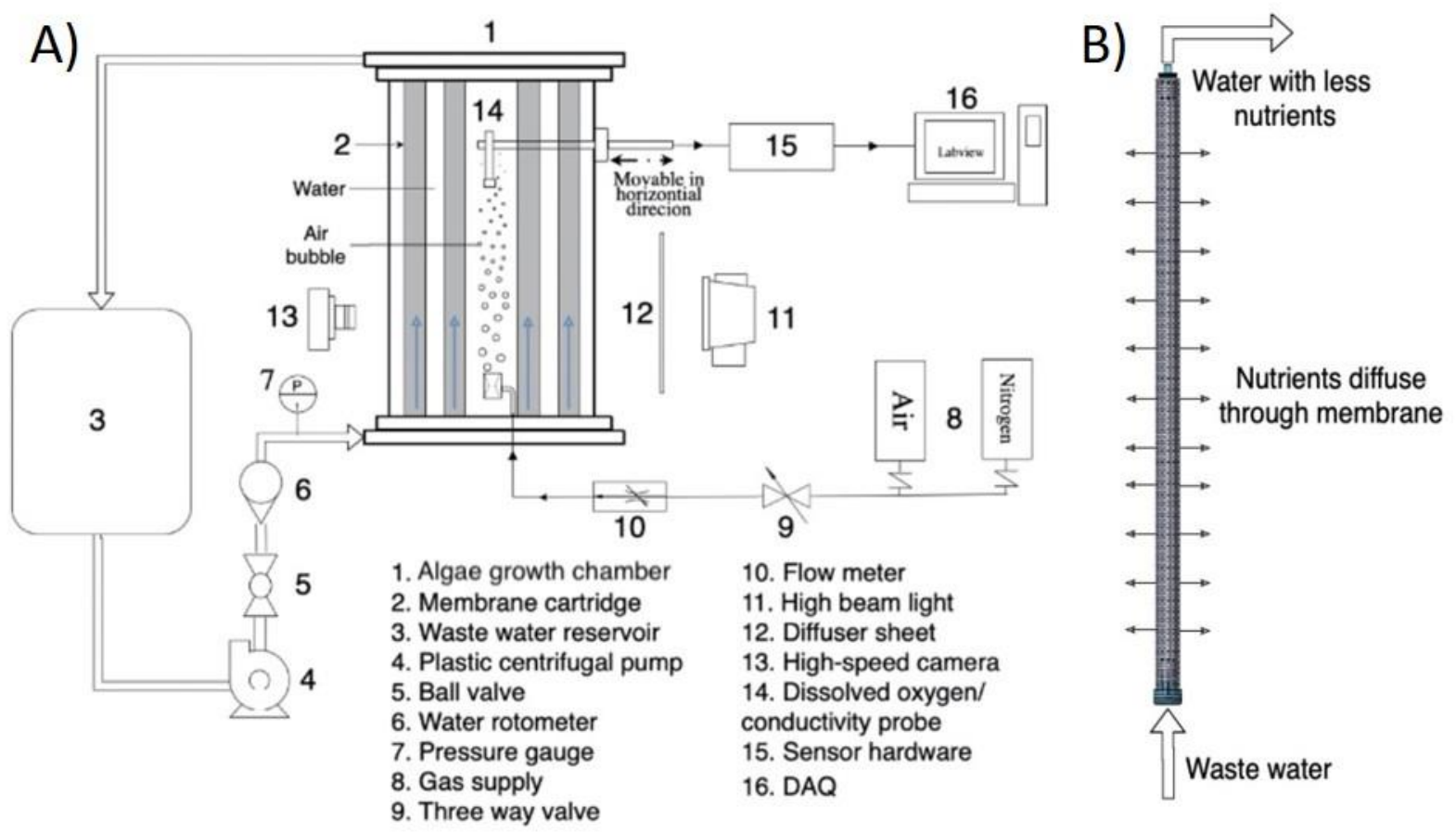

C)
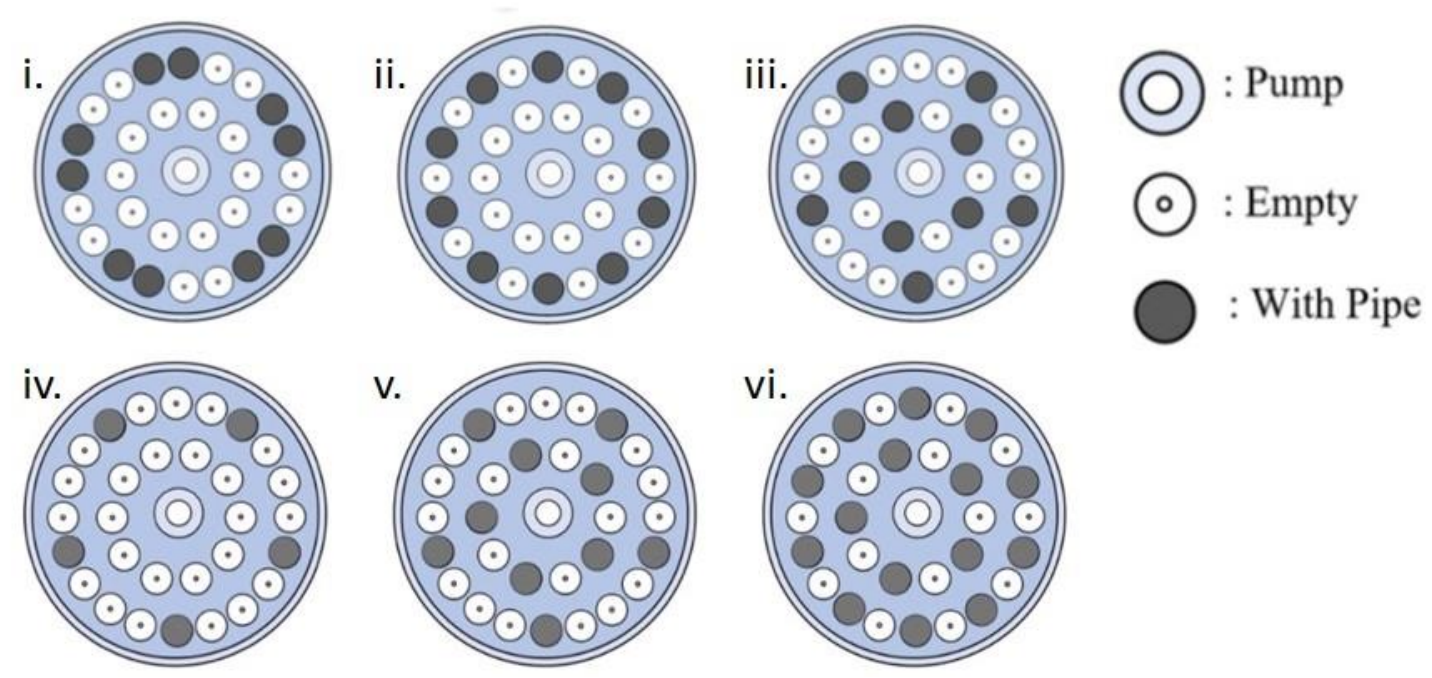

Figure 1: Overview of photobioreactor design and experimental setup used in this study. A) System schematic with algal growth chamber (1), wastewater reservoir (3) and Data Acquisition Options (DAQ) (16). B) Close-up of membrane cartridge unit for nutrient removal. Note that the reactor can accommodate up to 30 of these cartridges inside the chamber. C) Experimental setup of nutrient removal cartridge arrangements in this study. i.-iii.) Experiments 1-3; iv.-vi.) Experiments 4-5. 
Experimental Design

Aeration and Mixing Experiments

We conducted three experiments to gain insights into aeration and mixing within the reactor chamber. Specifically, we manipulated air flow rates under a range of internal reactor geometries and measured dissolved oxygen (DO) concentrations inside the chamber. From this data, we were able to calculate oxygen mass transfer rates. Additionally, we conducted two-phase flow experiments using high speed video acquisitions of the bubble column created in the reactor chamber and analyzed gas void fraction as a function of air flow rate using high speed video analysis.

For Experiments 1 and 2, we reduced DO in the chamber using nitrogen until we reached levels of approximately $0.8 \mathrm{mg} / \mathrm{L}$. We then sparged oxygen into the system through an airlift pump, designed to provide mixing using the swirling effect of bubble dynamics, until saturation was reached. Based on Henry's law, we calculated the saturated dissolved oxygen concentration to be roughly $9.1 \mathrm{mg} / \mathrm{L}$ at room temperature $\left(21^{\circ} \mathrm{C}\right)$ and standard pressure. This agreed with the experimental data, which found that the dissolved oxygen concentration at equilibrium was around $9.1 \mathrm{mg} / \mathrm{L}$. DO levels were measured continuously with a temporal resolution of one second using a galvanic dissolved oxygen probe with an accuracy of $\pm 0.05 \mathrm{mg} / \mathrm{L}$.

For each test, the total water flow rate as well as the air injection flow rate was held constant using a centrifugal pump and air regulator, respectively. The water and air flow rates were measured using a FL50000 rotameter (OMEGA) and OMEGA FMA 1612A flowmeter (OMEGA) respectively. The tank and reservoir conductivity were each measured using an Atlas Scientific K1.0 E.C probe connected to LABVIEW sampled at $1 \mathrm{~Hz}$. The reservoir water pressure was measured using a Winters PFQ pressure gauge. Additionally, the range and corresponding error for each instrument is shown in Table 1. We encountered noise in our measurements due to air bubbles in the reactor that interfered with the dissolved oxygen probe. To reduce the noise from the data, a Savitzky-Golay filter was applied. This filter has a built-in Matlab function and was used to smooth out the signal using a least square regression.

Table 1: Instrumentation range and uncertainty

\begin{tabular}{|l|l|l|}
\hline Instrument & Range & Error \\
\hline
\end{tabular}




\begin{tabular}{|l|l|l|}
\hline OMEGA FL 50000 Rotameter & $2-20 \mathrm{LPM}$ & $2 \%$ - full scale \\
\hline $\begin{array}{l}\text { OMEGA FMA 1612A } \\
\text { Flowmeter }\end{array}$ & $0-500 \mathrm{SLM}$ & $0.8 \% \mathrm{rdg}+0.2 \% \mathrm{FS}$ \\
\hline $\begin{array}{l}\text { Atlas Scientific K 1.0 E.C. } \\
\text { probe }\end{array}$ & $5-200,000 \mu \mathrm{S} / \mathrm{cm}$ & $2 \%$ \\
\hline Winters PFQ Pressure Gauge & $0-30$ PSI & $2.5 \%$ - full scale \\
\hline
\end{tabular}

Experiment 1: DO distribution as a function of reactor geometry

We assessed the distribution of DO in a cross section of the reactor chamber with and without membrane cartridges present. The gas flow rate for all trials was set at $10 \mathrm{~L} / \mathrm{min}$. The radial profile of DO measurements provides a representation of the mass transfer phenomenon occurring across the bioreactor's diameter. The bioreactor's inner diameter is $30 \mathrm{~cm}$ and we assessed five data points across this diameter. The radial profile was recorded every $170 \mathrm{~s}$. Additionally, ten $5 \mathrm{~cm}$ acrylic pipes were inserted into the bioreactor in different configurations. The goal was to determine whether the internal geometry of the bioreactor would affect mixing. The various patterns are illustrated in Figure 1C iFigures 1i-iii. These patterns were chosen because they are symmetrical and provide a uniform structure for measurement.

\section{Experiment 2: DO mass transfer as a function of air flow rate}

Aeration of a liquid by a photobioreactor can be characterized as the interfacial mass transfer between the liquid and the gas interface. Therefore, we assessed DO mass transfer in the reactor chamber using gas flow rates ranging from $2.5 \mathrm{~L} / \mathrm{min}$ to $15 \mathrm{~L} / \mathrm{min}$ with $2.5 \mathrm{~L} / \mathrm{min}$ increments. From these trials we were able to calculate saturation time and mass transfer rates (for details on calculation see below). The true mass transfer coefficient is difficult to measure and estimate independently; however, the effective interfacial area can be mathematically determined using different heuristics techniques (Lewis and Whitman, 1924). We therefore explored the most common models typically applied to this problem in order to find the best fit (Table 2).

Table 2: Summary of common overall mass transfer coefficient equation for bubble column

\section{Author}

\section{Equation}




\begin{tabular}{|c|c|}
\hline Lewis (1924) (Lewis and Whitman, 1924) & $k_{L}=\frac{D_{A B}}{\delta_{\mathrm{L}}}$ \\
\hline Higbie (1935) (Higbie, 1935) & $\overline{k_{L}}=2 \sqrt{\frac{D_{V}}{\pi t_{T}}}=1.13 \sqrt{\frac{D_{V}}{t_{T}}}$ \\
\hline Danckwarts (1955) (Danckwerts, 1955) & $k_{L}=\left(D_{A B} s\right)^{0.5}$ \\
\hline Linek (2005) (Linek et al., 2005) & $k_{L}=0.448\left(\frac{P \rho}{V}\right)^{0.25}\left(\frac{D_{L}}{r}\right)^{0.5}$ \\
\hline $\begin{array}{l}\text { Kawase and Moo Young (1991) (Kawase and } \\
\text { Moo-Young, 1991) }\end{array}$ & $k_{L} a=\frac{7 C F \sqrt{D_{A}} u_{g} \rho_{L}^{0.85} \sqrt{g}}{\mu_{B}^{0.25} \sigma^{0.6} d_{c}^{0.17}}$ \\
\hline Ferreira (2012) (Ferreira et al., 2012) & $k_{L} a=3372 \sqrt{\frac{D_{L}}{\pi} \sqrt{\frac{u_{G}^{1.87} g}{\mu_{l} \mu^{0.24}}}}$ \\
\hline Calderbank (1958) (Calderbank, 1958) & $k_{L}=0.422 N_{S C}^{-\frac{2}{3}}\left(\frac{\Delta \rho \mu_{c} g}{\rho_{c}^{2}}\right)^{1 / 3}$ \\
\hline Levich (1962) (Levich, 1962) & $k_{L}=\frac{D^{0.5} \rho^{0.5}}{\sigma^{0.5} v_{o}^{1.5}}$ \\
\hline Godbole (1984) (Godbole et al., 1984) & $k_{L}=0.146\left(j_{g}^{0.71}\right)\left(v^{-0.49}\right)$ \\
\hline Heijnen (1984) (Heijnen and Van't Riet, 1984) & $k_{L} a=0.32 j_{g}^{0.7}$ \\
\hline Kawase (1987) (Kawase et al., 1987) & $S h=0.63 * \frac{1}{\sqrt{\pi}} \sqrt{1.07} S c^{\frac{1}{2}} \operatorname{Re}^{\frac{3}{4}} F r^{\frac{7}{60}} B o^{\frac{3}{5}}$ \\
\hline Nakanoh (1980) (Nakanoh and Yoshida, 1980) & $k_{L}=\frac{0.09 D_{C}}{d_{\text {pipe }}} S c^{\frac{1}{2}} B o^{\frac{3}{4}} G a^{0.39} \mathrm{Fr}$ \\
\hline
\end{tabular}

\section{Experiment 3: Bubble pattern characterization and void fraction}

To analyze bubble column characteristics and measure void fraction as a function of gas flow rate, a Photron high-speed digital video camera was used to capture the regime of the twophase flow. Using custom MATLAB code, the void fraction at a given flow rate was determined based on individual frame analysis. To increase the system's ability to accurately read the void fraction, the image was captured at multiple locations within the reactor. These patterns were chosen because they are symmetrical and provide a uniform structure for measurement. Since the camera captured the image and showed it in two dimensions, the area of the gas portion over the total area would be equivalent to the void fraction of the system. The MATLAB program first 
converted the captured image to a binary image. The white color represents gas and the black color represents water. By dividing the white colored pixels of the image over the total pixels of the image, the void fraction of the system can be found. The void fraction is strongly related to the bubble size and the flow pattern.

\section{Membrane Cartridge Mass Transfer Experiments}

The photobioreactor we developed is designed to effectively transfer nutrients from the wastewater stream into the algal bioreactor column (Fig. 1). The membrane cartridge provides the interface between these two compartments and in Experiment 4 we analyzed mass transfer rates in real time, using artificial salt water (Instant Ocean ${ }^{\mathrm{TM}}$ SS15-10) gradients. In Experiment 5, we focused on the impact of the membrane cartridge geometry on mass transfer rate. The artificial sea salt Instant Ocean ${ }^{\mathrm{TM}}$ is a complex mixture of ions and, therefore, the relationship between concentration and conductivity had to be determined empirically using a conductivity probe (Atlas Scientific K 1.0 E.C. probe) Each probe was calibrated using eight solutions of known concentration of Instant Ocean using serial dilutions which were used to plot a calibration curve; this curve was then added to the LabVIEW data acquisition system.

Experiment 4: Optimization of air, water flow and concentration gradient for maximizing mass $\underline{\text { transfer rates }}$

We developed a comprehensive experimental matrix to determine the optimal operating conditions that produce the highest mass transfer rate across a range of water and air flow rates as well as salt gradients (Table 3). For each test, the concentration of the Instant Ocean salts was adjusted. Additionally, the number of membranes in the reactor chamber was 15 (50\% capacity). The membranes used were Fisher Scientific Cellulose Dialysis tubing with a quoted pore diameter of $4.8 \mathrm{~nm}(\mathrm{~S} 25645 \mathrm{~B})$. The reactor was operated for 1 hour for each test.

Table 3: Operating conditions tested for salt water trials

\begin{tabular}{|l|l|}
\hline Total Water Flow Rate (LPM) & $3,6,9,12,15$ \\
\hline Air Injection Flow Rate (LPM) & $0.5,5,14$ \\
\hline Reservoir Initial Instant Ocean Concentration (ppt) & $1,2,5$ \\
\hline
\end{tabular}




\section{Experiment 5: Impact of membrane cartridge geometry on mass transfer rate}

We manipulated the number of membranes in a separate set of trials in order to gain insight into the effect of the membrane volume ratio on the mass transfer rate. For these experiments the reactor was operated at 9 LPM of saltwater flow with 5 LPM of air injection and with a saltwater concentration gradient of $1 \mathrm{ppt}$. The configurations for each test are shown in Figure 1. A volume ratio was used to quantify the volume of membrane cartridges used in the reactor per volume of algae chamber fluid defined as:

$$
V R=\frac{V_{m}}{V_{R B}}
$$

where, $V_{m}$ is the filled volume of membranes being used and $V_{R B}$ is the volume of water in the reactor body.

Signal Processing and Data Analysis

Oxygen mass transfer calculations (Experiments 1-3): The mass transfer coefficient $k_{L} a$ was based on the configuration and the hydrodynamics of the bioreactor system. The value of the mass transfer coefficient was presumed to be the instant mass balance of the solute and is represented as follows:

$$
\frac{d C_{L}}{d t}=k_{L} a *\left(C_{s}-C_{L}\right)
$$

where $C_{L}$ is the concentration of the dissolved oxygen in the water at time $t$, and $C_{S}$ is the concentration of the dissolved oxygen at a saturated state. The bioreactor setup is an adiabatic system and we therefore assumed that the ambient temperature was constant at $\left(21^{\circ} \mathrm{C}\right)$. The saturated dissolved oxygen was always set to be $9.1 \mathrm{mg} / \mathrm{L}$. As well, $k_{L} a$ is the overall mass transfer coefficient of the bioreactor system.

Adopting the work of Boyd (Boyd, 1979) and Colt (Colt, 2012), the mass transfer coefficient was calculated through linear regression analysis. With the integration of Equation (2), the overall mass transfer coefficient, $k_{L} a$, relative to the overall volume in the bioreactor is expressed as follows:

$$
k_{L} a=\ln \left(\frac{C_{S}-C_{0}}{C_{S}-C_{L}}\right) * \frac{1}{t}
$$

$C_{0}$ is the initial concentration of the dissolved oxygen in the water. The mass transfer coefficient can be further approximated by multiplying it with a correction factor due to the water temperature. The resulting relationship is expressed as follows: 


$$
k_{L} a=\left(k_{L} a\right)_{20} \theta^{T-20}
$$

where $\theta$ is the correction factor of the temperature and is always set as 1.024 , as all experiments were conducted at standard temperature. $\mathrm{T}$ is the temperature of the water during the test.

Salt mass transfer calculation (Experiments 4 and 5): To evaluate the mass transfer through the membrane stack, the slope of the conductivity measured in the algae reactor was used. As air bubble injection introduced noise into the conductivity measurements, signals were processed in MATLAB using an upper and lower envelope of the sampled conductivity and we extracted the upper envelope for further processing. This slope (mass transfer rate, $\mathbf{J}$ (Equation 8 ) - $\mathbf{J}$ is the measured salt transfer rate, $\Delta x$ is the membrane thickness and $\mathrm{A}$ is the surface area of exposed membrane in the cartridge), was then used to calculate the diffusivity constant, D (Equation 8), which is a function of the concentration gradient, membrane surface area, and water velocity at the membrane surface (Equations 5-8). D was then used to determine the Sherwood number (Equation $9-d$ is the tube diameter and $v$ is the average fluid velocity) and the Reynolds number (Equation $10-\rho$ is the water density and $\mu$ is the fluid viscosity), two non-dimensional parameters, allowing unlimited scaling of the reactor prototype.

$$
\begin{aligned}
& \Delta C_{\text {in }}=C_{\text {initial,Res }}-C_{\text {initial }, \text { Col }} \\
& \Delta C_{\text {out }}=C_{\text {final,Res }}-C_{\text {final,Col }} \\
& \Delta C_{\text {mean }}=\frac{\Delta C_{\text {in }}-\Delta C_{\text {out }}}{\ln \left(\frac{\Delta C_{\text {in }}}{\Delta C_{\text {out }}}\right)} \\
& D=\frac{J \Delta x}{A \Delta C_{\text {mean }}} \\
& S h=1.62\left(\frac{d v}{D}\right)^{\frac{1}{3}} \\
& R e=\frac{\rho v d}{\mu}
\end{aligned}
$$




\section{ACKNOWLEDGMENTS}

We would like to acknowledge the help of the following students, who contributed to this project: Mina Abdul Ghani, Kyle Maddden, John Zaleski-Cox.

\section{DECLARATIONS}

Ethics approval and consent to participate - NOT APPLICABLE

Consent for publication - NOT APPLICABLE

Availability of data and materials - NOT APPLICABLE

Competing interests - The authors declare that they have no competing interests

Funding - This work was supported by funds from the George Weston Foundation through the Seeding Food Innovation Grant to AH (053994).

Authors' contributions - AH and WA designed the experiments described here and wrote the manuscript, JC, KC, AE, KN and JR conducted the mass transfer trials and oxygen trials and helped analyze the data and write the ma nuscript. 


\section{REFERENCES}

Ahmed, N., Thompson, S., Glaser, M., 2019. Global Aquaculture Productivity, Environmental Sustainability, and Climate Change Adaptability. Environ Manage 63, 159-172.

Ariadi, H., Fadjar, M., Mahmudi, M., Supriatna, 2019. The relationships between water quality parameters and the growth rate of white shrimp (Litopenaeus vannamei) in intensive ponds. Aquaculture, Aquarium, Conservation \& Legislation 12, 2103-2116.

Barbu, M., Ceanhî, E., Caraman, S., 2016. Water Quality Modeling and Control in Recirculating Aquaculture Systems.

Bjorndal, T., Tusvik, A., 2019. Economic analysis of land based farming of salmon. Aquacult Econ Manag 23, 449-475.

Bosca, C., Dauta, A., Marvalin, O., 1991. Intensive outdoor algal cultures: How mixing enhances the photosynthetic production rate. Bioresource Technology 38, 185-188.

Boyd, C.E., 1979. Water quality in warmwater fish ponds. Auburn University, Agricultural Experiment Station.

Brune, D.E., Lundquist, T.J., Benemann, J.R., 2009. Microalgal Biomass for Greenhouse Gas Reductions: Potential for Replacement of Fossil Fuels and Animal Feeds. Journal of Environmental Engineering 135, 1136-1144.

Calderbank, P.H., 1958. Physical Rate Processes in Industrial Fermentation. Part 1. The Interfacial Area in Gas-liquid Contacting with Mechanical Agitation. Trans. Inst. Chem. Eng. 36, 443-463.

Chacon-Lee, T.L., Gonzalez-Marino, G.E., 2010. Microalgae for "Healthy" Foods-Possibilities and Challenges. Compr Rev Food Sci F 9, 655-675.

Chisti, Y., 2007. Biodiesel from microalgae. Biotechnology Advances 25, 294-306. 
Chisti, Y., 2008. Biodiesel from microalgae beats bioethanol. Trends in Biotechnology 26, 126131.

Choi, H.-J., Lee, S.-M., 2012. Effects of Microalgae on the Removal of Nutrients from Wastewater: Various Concentrations of Chlorella vulgaris. Environmental Engineering Research $17,3-8$.

Colt, J., 2012. 2 - Solubility of Atmospheric Gases in Brackish and Marine Waters, in: J. Colt (Ed.), Computation of Dissolved Gas Concentration in Water as Functions of Temperature, Salinity and Pressure (Second Edition). Elsevier, London, 73-131.

Costello, C., Cao, L., Gelcich, S., Cisneros-Mata, M.Á., Free, C.M., Froehlich, H.E., Golden, C.D., Ishimura, G., Maier, J., Macadam-Somer, I., Mangin, T., Melnychuk, M.C., Miyahara, M., de Moor, C.L., Naylor, R., Nøstbakken, L., Ojea, E., O’Reilly, E., Parma, A.M., Plantinga, A.J., Thilsted, S.H., Lubchenco, J., 2020. The future of food from the sea. Nature 588, 95-100.

Couvert, A., Bastoul, D., Roustan, M., Chatellier, P., 2004. Hydrodynamic and mass transfer study in a rectangular three-phase air-lift loop reactor. Chemical Engineering and Processing: Process Intensification 43, 1381-1387.

Cui, Z.F., Chang, S., Fane, A.G., 2003. The use of gas bubbling to enhance membrane processes. Journal of Membrane Science 221, 1-35.

Danckwerts, P.V., 1955. Gas absorption accompanied by chemical reaction. AIChE Journal 1, 456-463.

de la Noue, J., de Pauw, N., 1988. The potential of microalgal biotechnology: A review of production and uses of microalgae. Biotechnology Advances 6, 725-770.

El-Sheekh, M.M., Farghl, A.A., Galal, H.R., Bayoumi, H.S., 2016. Bioremediation of different types of polluted water using microalgae. Rend Lincei-Sci Fis 27, 401-410.

Ferreira, A., Pereira, G., Teixeira, J.A., Rocha, F., 2012. Statistical tool combined with image analysis to characterize hydrodynamics and mass transfer in a bubble column. Chemical Engineering Journal 180, 216-228. 
Godbole, S.P., Schumpe, A., Shah, Y.T., Carr, N.L., 1984. Hydrodynamics and mass transfer in non-Newtonian solutions in a bubble column. AIChE Journal 30, 213-220.

Guedes, A.C., Amaro, H.M., Malcata, F.X., 2011. Microalgae as Sources of Carotenoids. Mar Drugs 9, 625-644.

Heijnen, J.J., Van't Riet, K., 1984. Mass transfer, mixing and heat transfer phenomena in low viscosity bubble column reactors. The Chemical Engineering Journal 28, B21-B42.

Higbie, R., 1935. The rate of absorption of a pure gas into a still liquid during short periods of exposure. Trans. Am. Inst. Chem. Eng.

Janssen, M., Tramper, J., Mur, L.R., Wijffels, R.H., 2003. Enclosed outdoor photobioreactors: Light regime, photosynthetic efficiency, scale-up, and future prospects. Biotechnology and Bioengineering 81, 193-210.

Javanmardian, M., Palsson, B.O., 1991. High-density photoautotrophic algal cultures: Design, construction, and operation of a novel photobioreactor system. Biotechnology and Bioengineering 38, 1182-1189.

Kawase, Y., Halard, B., Moo-Young, M., 1987. Theoretical prediction of volumetric mass transfer coefficients in bubble columns for Newtonian and non-Newtonian fluids. Chemical Engineering Science 42, 1609-1617.

Kawase, Y., Moo-Young, M., 1991. Oxygen transfer in slurry bioreactors. Biotechnology and Bioengineering 37, 960-966.

Lee, D.J., Kang, S.W., Park, J.H., Kim, S.H., Choi, I.W., Hwang, T.H., Lim, B.J., Jung, S.J., Park, H.N., Cho, J.S., Seo, D.C., 2015. Enhancement of Nutrient Removal in a Hybrid Constructed Wetland Utilizing an Electric Fan Air Blower with Renewable Energy of Solar and Wind Power. Journal of Chemistry 2015, 813827.

Levich, V.G., 1962. Physicochemical hydrodynamics. Prentice-Hall, Englewood Cliffs, N.J. 
Lewis, W.K., Whitman, W.G., 1924. Principles of Gas Absorption. Industrial \& Engineering Chemistry 16, 1215-1220.

Linek, V., Kordač, M., Moucha, T., 2005. Mechanism of mass transfer from bubbles in dispersions: Part II: Mass transfer coefficients in stirred gas-liquid reactor and bubble column. Chemical Engineering and Processing: Process Intensification 44, 121-130.

Martins, C.I.M., Eding, E.H., Verdegem, M.C.J., Heinsbroek, L.T.N., Schneider, O., Blancheton, J.P., d'Orbcastel, E.R., Verreth, J.A.J., 2010. New developments in recirculating aquaculture systems in Europe: A perspective on environmental sustainability. Aquacultural Engineering 43, 83-93.

Mohsenpour, S.F., Willoughby, N., 2016. Effect of CO2 aeration on cultivation of microalgae in luminescent photobioreactors. Biomass Bioenerg 85, 168-177.

Moreno-Garcia, L., Adjallé, K., Barnabé, S., Raghavan, G.S.V., 2017. Microalgae biomass production for a biorefinery system: Recent advances and the way towards sustainability. Renewable and Sustainable Energy Reviews 76, 493-506.

Nakanoh, M., Yoshida, F., 1980. Gas Absorption by Newtonian and Non-Newtonian Liquids in a Bubble Column. Industrial \& Engineering Chemistry Process Design and Development 19, 190195.

Renuka, N., Guldhe, A., Prasanna, R., Singh, P., Bux, F., 2018. Microalgae as multi-functional options in modern agriculture: current trends, prospects and challenges. Biotechnology Advances $36,1255-1273$.

Sánchez Mirón, A., Cerón García, M.-C., García Camacho, F., Molina Grima, E., Chisti, Y., 2002. Growth and biochemical characterization of microalgal biomass produced in bubble column and airlift photobioreactors: studies in fed-batch culture. Enzyme and Microbial Technology 31, 10151023.

Sathasivam, R., Ki, J.S., 2018. A Review of the Biological Activities of Microalgal Carotenoids and Their Potential Use in Healthcare and Cosmetic Industries. Mar Drugs 16. 
Schuster, C., Stelz, H., 1998. Reduction in the make-up water in semi-closed recirculating aquaculture systems. Aquacultural Engineering 17, 167-174.

Singh, R.N., Sharma, S., 2012. Development of suitable photobioreactor for algae production - A review. Renewable and Sustainable Energy Reviews 16, 2347-2353.

Spolaore, P., Joannis-Cassan, C., Duran, E., Isambert, A., 2006. Commercial applications of microalgae. Journal of Bioscience and Bioengineering 101, 87-96.

Tang, G., Suter, P., 2011. Vitamin A, Nutrition, and Health Values of Algae: Spirulina, Chlorella, and Dunaliella.

Timmons, M.B., Ebeling, J.M., 2010. Recirculating Aquaculture Systems. Aquaculture.

Ugwu, C.U., Aoyagi, H., Uchiyama, H., 2008. Photobioreactors for mass cultivation of algae. Bioresource Technology 99, 4021-4028.

van Rijn, J., 2013. Waste treatment in recirculating aquaculture systems. Aquacultural Engineering $53,49-56$.

Yang, Z., Pei, H., Han, F., Wang, Y., Hou, Q., Chen, Y., 2018. Effects of air bubble size on algal growth rate and lipid accumulation using fine-pore diffuser photobioreactors. Algal Research 32, 293-299.

Zhu, L., Wang, Z., Shu, Q., Takala, J., Hiltunen, E., Feng, P., Yuan, Z., 2013. Nutrient removal and biodiesel production by integration of freshwater algae cultivation with piggery wastewater treatment. Water Research 47, 4294-4302. 

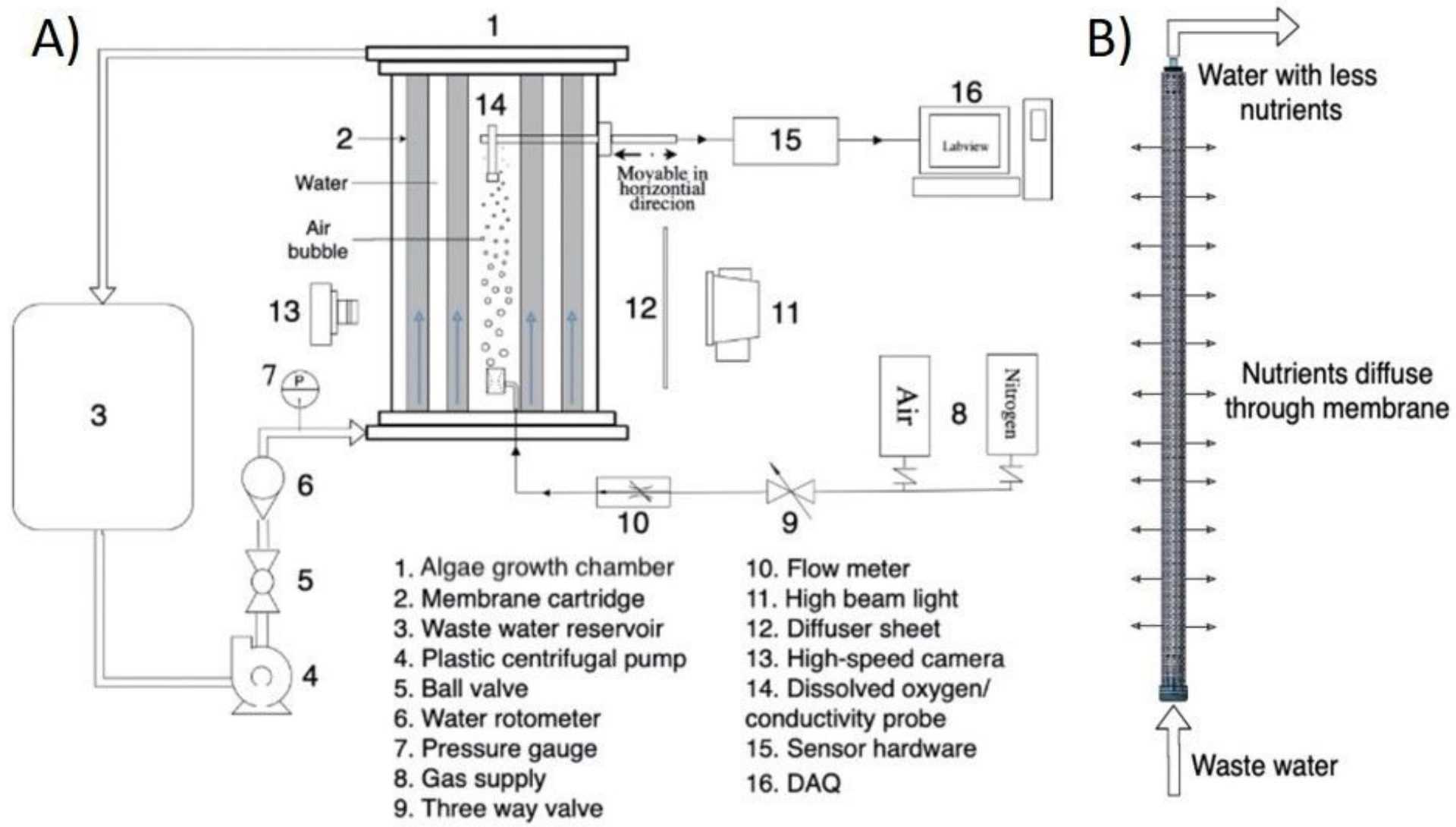

C)
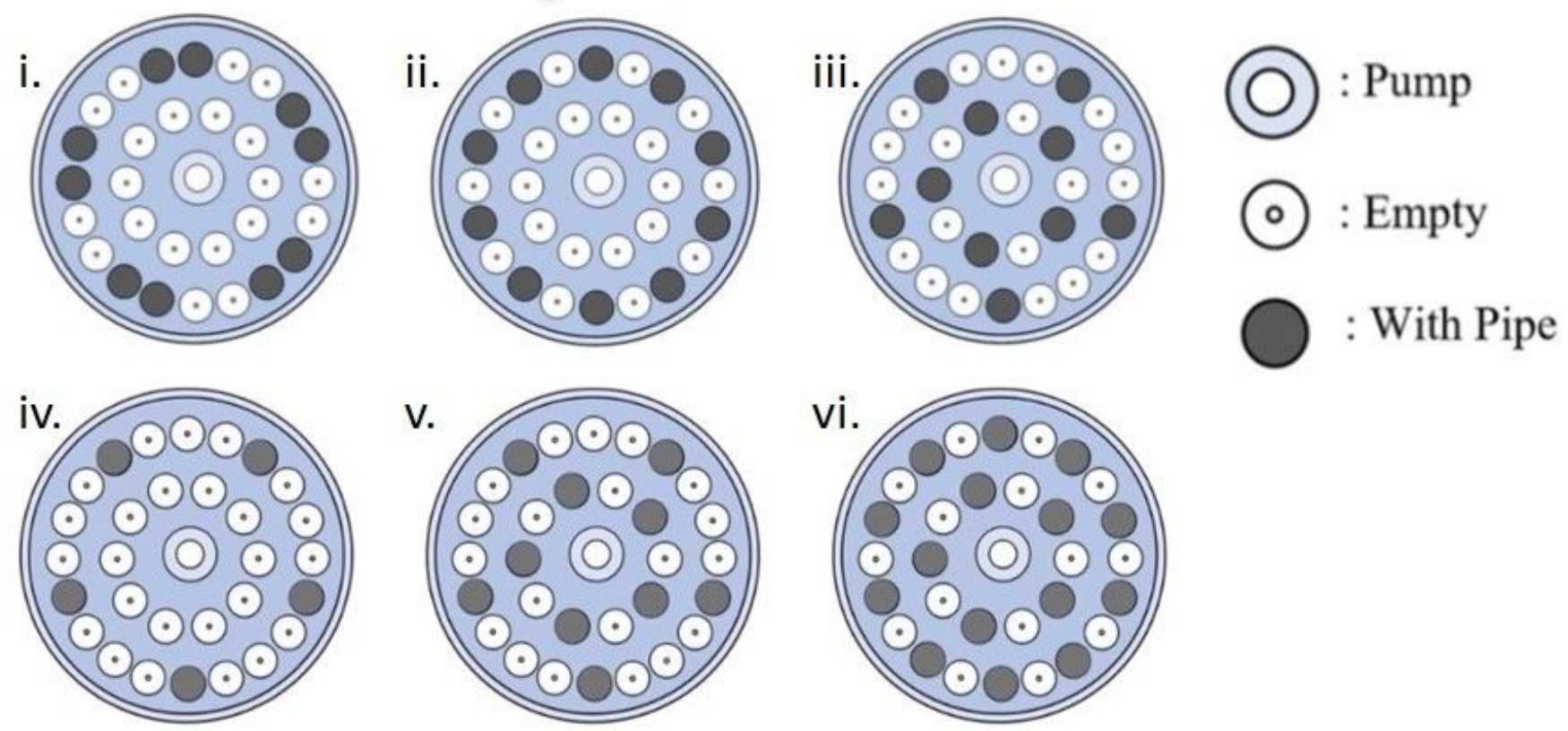

Figure 1

Overview of photobioreactor design and experimental setup used in this study. A) System schematic with algal growth chamber (1), wastewater reservoir (3) and Data Acquisition Options (DAQ) (16). B) Close-up of membrane cartridge unit for nutrient removal. Note that the reactor can accommodate up to 30 of 
these cartridges inside the chamber. C) Experimental setup of nutrient removal cartridge arrangements in this study. i.-iii.) Experiments 1-3; iv.-vi.) Experiments 4-5.
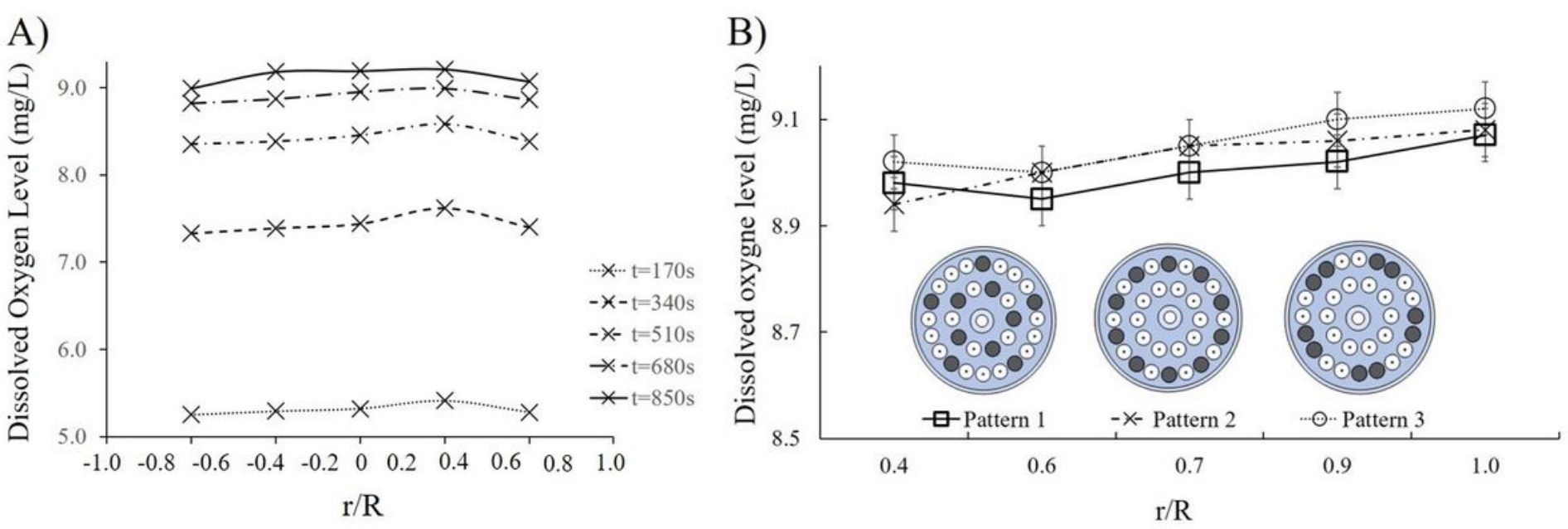

\section{Figure 2}

Radial profiles of dissoved oxygen levels within the reactor chamber. A) Radial profile across the full diameter of the reacor chamber without membrane cartridges measured at five time points from 170s up to saturation at $850 \mathrm{~s}$. B) Radial profile across one half of the reactor chamber with three different membrane cartridge patterns present (used cartridges in dark blue). 
A)

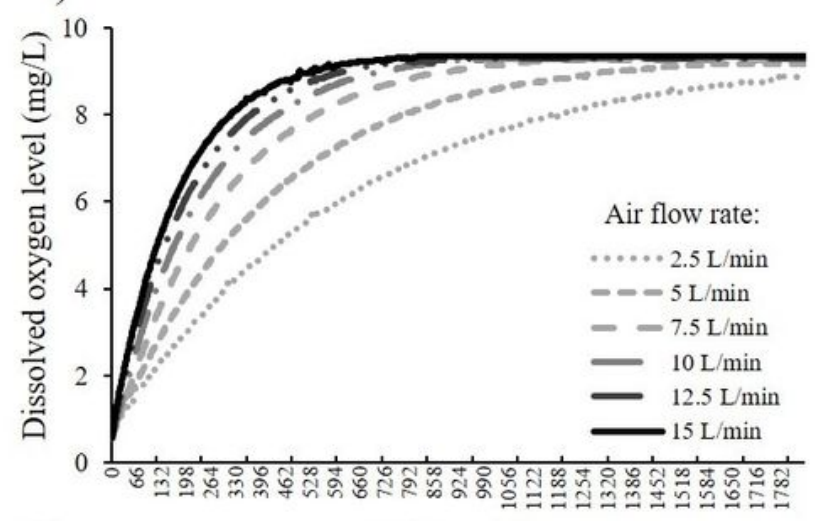

C)

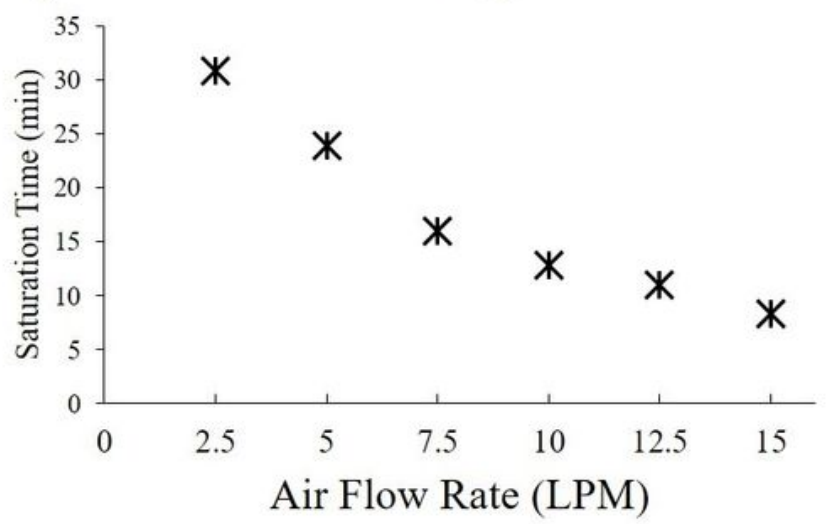

B)

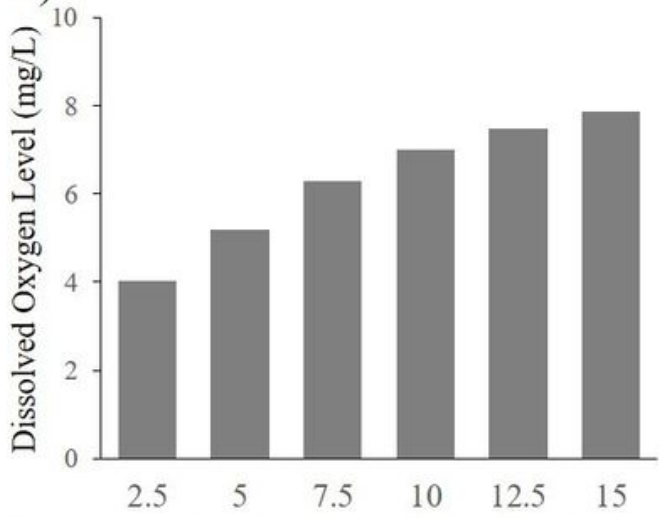

D) Air Flow Rate (LPM)

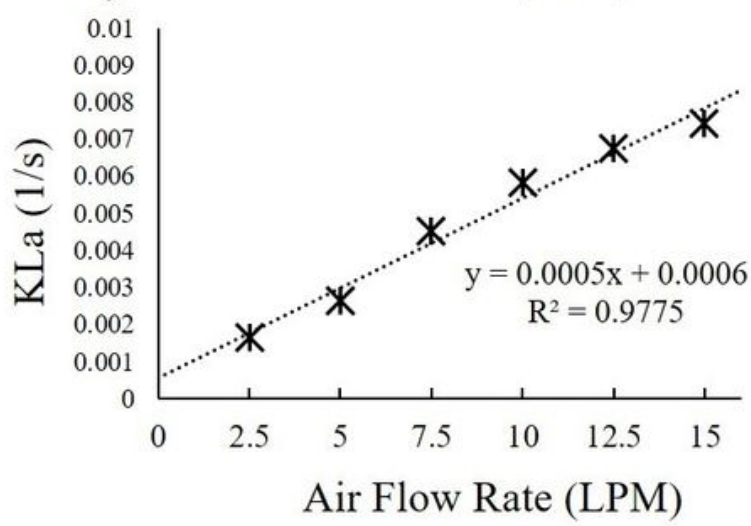

E)

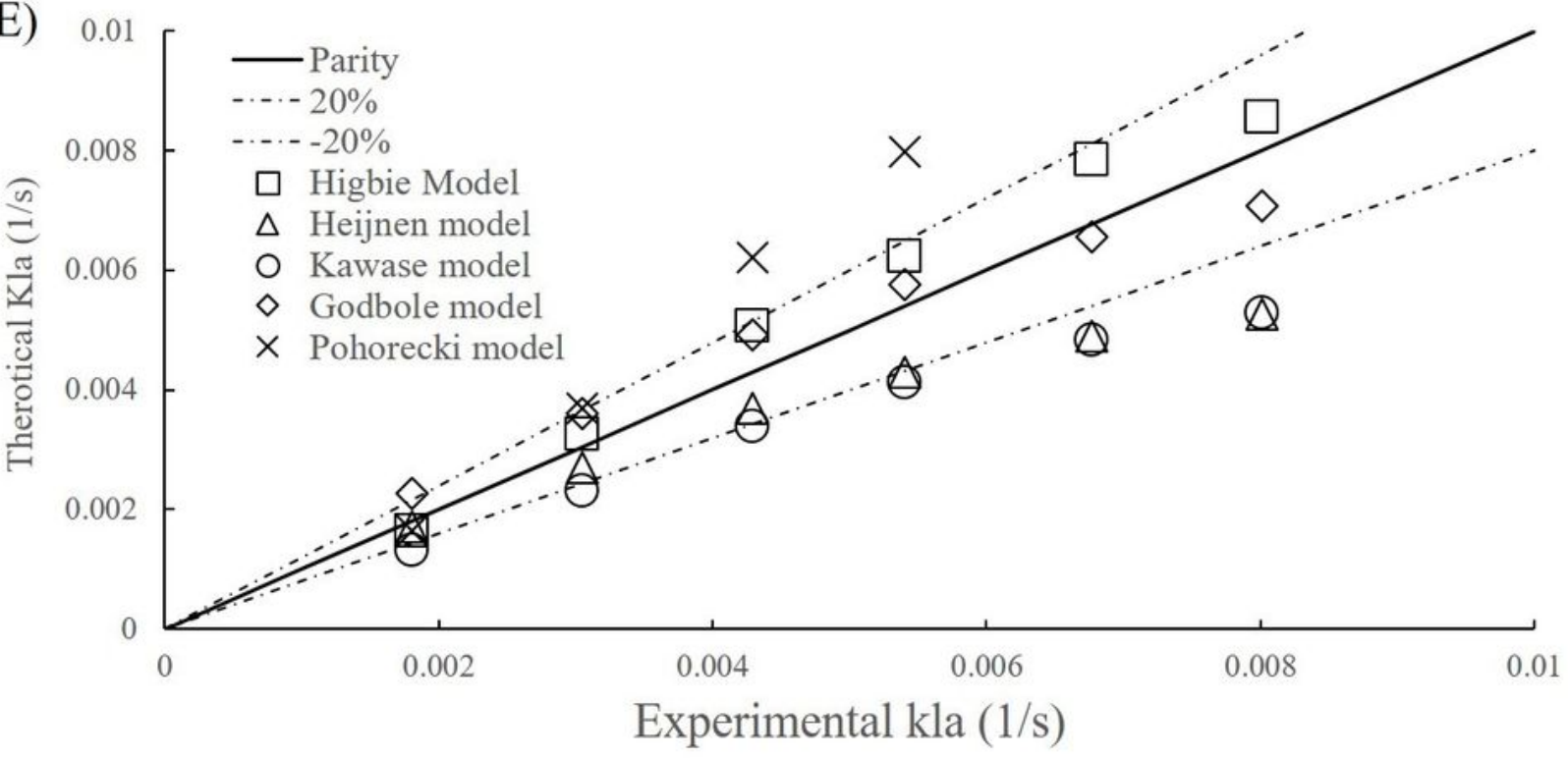

Figure 3

Dissolved oxygen (DO) level at various gas flow rates within the reactor chamber. A) DO as a function of time and six air flow rates. B) Average DO as a function of air flow rates. C) Saturation time (min) as a function of air flow rates. D) Calculated oxygen mass transfer rate as a function of air flow rate with linear regression model. E) Fitting of existing mass transfer models to the existing data. 

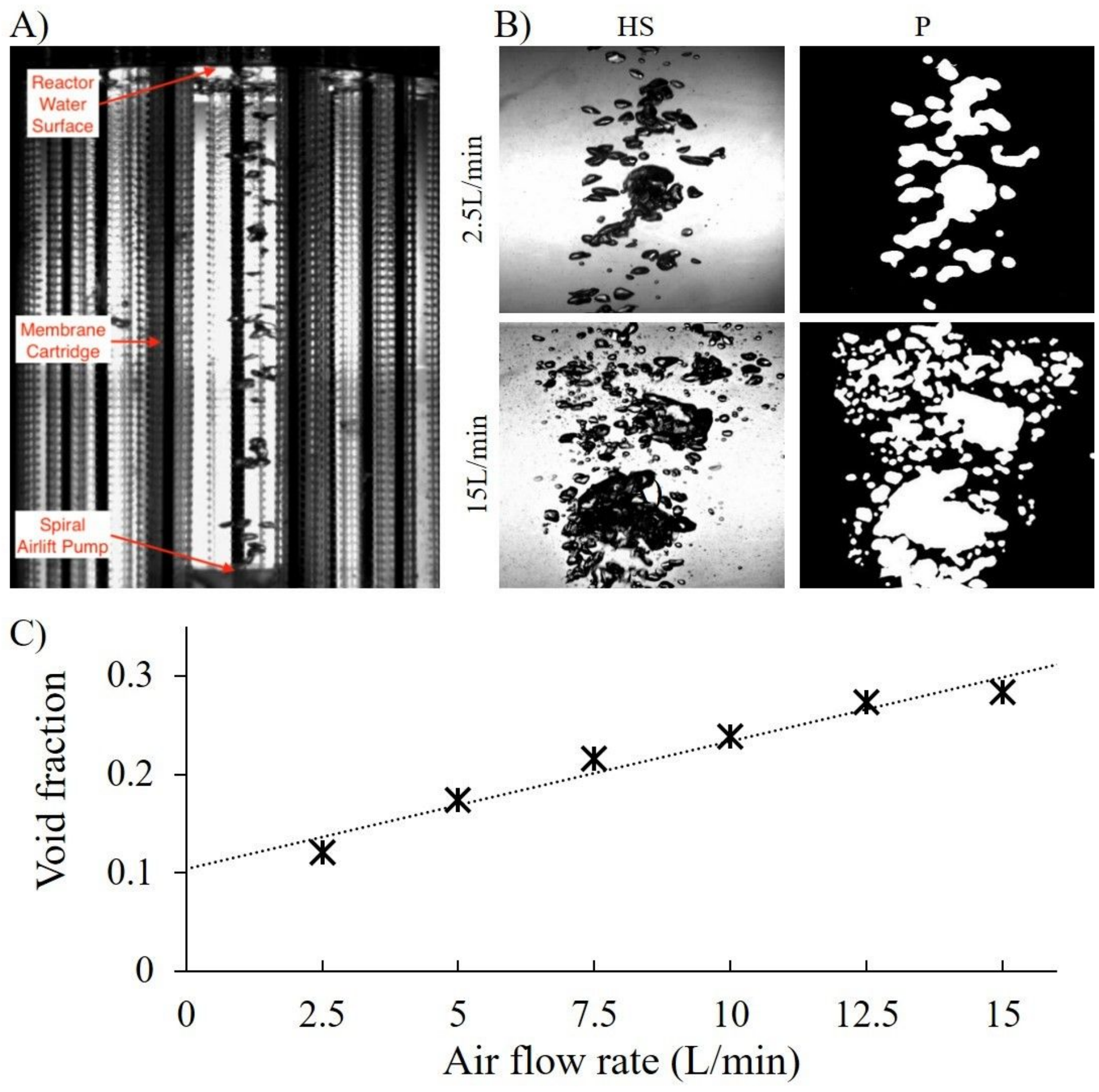

Figure 4

Multiphase flow visualization during reactor operation $(A)$ and empirical assessment of air void fraction with the reactor chamber $(B, C)$. A) image of reactor chamber using high speed camera setup. $B$ ) Representative high speed frames of lowest $(2.5 \mathrm{~L} / \mathrm{min})$ and highest $(15 \mathrm{~L} / \mathrm{min})$ air flow rates with processed images used for analysis. Complete set of representative images across the entire range can be found in Supplement 1. 

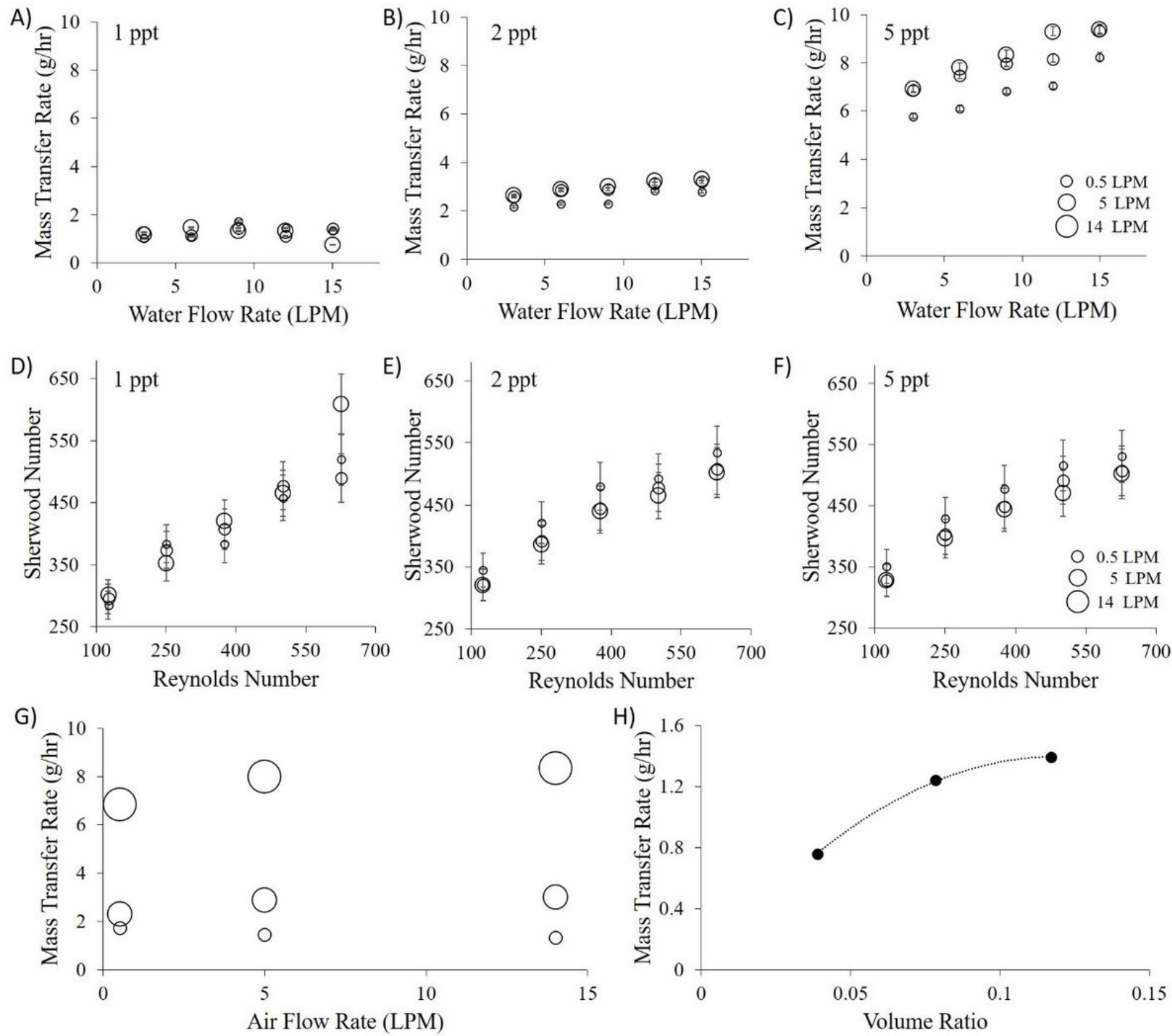

\section{Figure 5}

Salt mass transfer rates as a result of five water flow rates and three air flow rates across three salinity gradients (A-C). Calculated non-dimensional plots based on mass transfer values across three salinity gradients (D-F). G) Summary of mass transfer rates as a function of three air flow rates (0.5LPM, 5LPM and 14LPM) and three salinity gradients (1ppt, 2ppt and 5ppt - represented by increasing sized circles) with membrane cartridges present. $\mathrm{H}$ ) Mass transfer rate across membrane cartridges as a function of volume ratio of cartridges occupied. 